\title{
Spatial Spillover Effect of Green Water Use Efficiency and its Influence Factor: New Evidence from Yellow River Economic Belt, China
}

\section{Shen Zhong}

Harbin University of Commerce

Jian Li

Harbin University of Commerce

Hongmei Wen ( $D$ 102242@hrbcu.edu.cn )

Harbin University of Commerce

Hongli Wang

Harbin University of Commerce

\section{Research Article}

Keywords: green water use efficiency, global Malmquist-Luenberge productivity index, spatial spillover, Yellow River Economic Belt

Posted Date: February 15th, 2021

DOI: https://doi.org/10.21203/rs.3.rs-188354/v1

License: (c) (i) This work is licensed under a Creative Commons Attribution 4.0 International License. Read Full License 
1. Shen Zhong, School of Finance, Harbin University of Commerce, China; address: No.1, Xuehai street, Songbei District, Harbin, Heilongjiang Province, China; 102714@hrbcu.edu.cn

2. Jian Li, School of Finance, Harbin University of Commerce, China; address: No.1, Xuehai street, Songbei District, Harbin, Heilongjiang Province, China; lijian@hrbcu.du.cn

3. Hongmei Wen [corresponding author]; professor; School of Finance, Harbin University of Commerce; corresponding address: No.1 Xuehai street, Songbei District, Harbin, Heilongjiang Province, China. Telephone: +86 15145044039; 102242@hrbcu.edu.cn

4. Hongli Wang, School of Finance, Harbin University of Commerce, China; address: No.1, Xuehai street, Songbei District, Harbin, Heilongjiang Province, China; wanghongli@hrbcu.edu.cn

\section{Ethics approval and consent to participate:}

This study involves the macro data of human economy and society. All the data are from the official statistical yearbook. The data collection process is in line with the ethical and moral standards. The research method of this study is spatial econometric method, and there is no need for ethical approval and animal experiment content. The author guarantees that the process, content and conclusion of this study do not violate the theory and moral principles.

\section{Consent of publication:}

Not applicable.

\section{Availablity of data and materials:}

The data that support the findings of this study are available from [www.cnki.net] but restrictions apply to the availablity of these data, which were used under license for the current study, and so are not publicly available. Data are however available from the authors upon reasonable request and with permission of [www.cnki.net].

\section{Competing interests:}

We declare that we have no financial and personal relationships with other people or organizations that can inappropriately influence our work, there is no professional or other personal interest of any nature or kind in any product, service and/or company that could be construed as influencing the position presented in, or the review of, the manuscript entitled "Spatial Spillover Effect of Green Water Use Efficiency and its Influence Factor: New Evidence from Yellow River Economic Belt, China".

\section{Funding:}

We thank "young innovative talents" program of Harbin University of Commerce [2019CX16]; Graduate innovation project of Harbin University of Commerce [YJSCX2020-647HSD].

\section{Authors' contributions:}

SZ provides the research route, theoretical analysis, and important contribute for the subsequent revision and language of the manuscript. JL is mainly responsible for data collection and collation, empirical analysis, and writed the first draft of the manuscript. HMW provides software operation guidance and manuscript modification. HLW is mainly 
responsible for data collection and collation. All authors read and approved the final manuscript.

\section{Abstract}

The shortage of fresh water resources is an important factor restriction the sustainable development of the Yellow River Economic Belt (YREB). Increasing Green Water-Use Efficiency (GWUE) is a necessary way to ensure the sustainable development of water resources. Therefore, it is of theoretical significance and practical value to measure GWUE and investigate its influencing factors. Based on the panel data of 98 cities in YREB from 2005-2018, this paper first measures GWUE by global Malmqusit approach which contains unexpected output, and decomposes the comprehensive efficiency into Technological Change (TC), Pure Technical Efficiency Change (PEC) and Scale Efficiency Change (SEC). Furthermore, the spatial correlation of GWUE and decompositon indexs are analyzed by using the spatial Durbin model, and the influence of other interpretations on GWUE is analyzed. The empirical results show that: (1) The average annual growth rate of WGUE is $7.86 \%$ during 2005-2018, and the average annual growth rate of TC, PEC, SEC is $2.57 \%$, $3.87 \%$ and $1.84 \%$ respectively, which all contribute to the improvement of WGUE. (2) GMLPI, TC, PEC, SEC all show the agglomeration characteristics of "high-high" or "low-low", and the GWUE of the local city will be affected by the same direction of the surrounding cities. Every 1\% increase in GMLPI, TC, PEC and SEC of surrounding cities will lead to the corresponding index growth of about $0.321 \%, 0.393 \%, 0.244 \%$ and $0.358 \%$ respectively. (3) Industrial structure and foreign direct investment have a negative total effect on GWUE. The expenditure on science and technology, education and population density have significatly promoted technological progress both the local city and surrounding cities. Infrastructure has a significant positive effect on the pure technical efficiency of the city. This paper hodls that the government should strengthen cooperation and technical innovation, optimize foreign capital structure and industrial structure.

Keywords: green water use efficiency; global Malmquist-Luenberge productivity index; spatial spillover; Yellow River Economic Belt

\section{Introdution}

The Yellow River Economic Belt (YREB) of China spans seven provinces and two autonomous regions. According to the China Statistical Yearbook 2019, the area of ancient land is 3.58 million $\mathrm{KM}^{2}$ (accounting for $37.34 \%$ of China's inland), and GDP 23854.6 billion yuan (accounting for $26.5 \%$ of China), 420.37 million people (accounting for $30.1 \%$ of the country's population). The economic development of YREB plays an important role in China. But its scale and efficiency is not prominent in the economic development, one of the main reasons is constrained by natural resources, among which the most significant impact by shortage of water resources. According to China Statistical Yearbook 2018, the per capita freshwater resources of the YREB is $933.7 \mathrm{~m}^{3}$, only $45 \%$ of the national average level, and the total water consumption is 127.56 billion $\mathrm{m}^{3}$ (accounting for $21.1 \%$ of China). Although the YREB is backed by the Yellow River, due to the influence of low precipitation and poor water quality, fresh water resources are still scare seriously compared with other basins. Under the background that fresh water supply cannot be effectively increased, improving the utilization efficiency of water resources is a necessary way to ensure the sustainable development of 
YREB. Therefore, the measurement of water-use efficiency has full theoretical significance and practical value. Therefore, on the basis of existing research, this paper takes industrial wastewater discharge as an unexpected output into the model, and measures the Green Water-Use Efficiency (GWUE) of the Yellow River Economic Belt.

Furthermore, in order to provide policy makers and enterprise decision makers with practical ways to improve GWUE, this paper analyzes the influencing factors of GWUE. According to the existing research, industrial structure (Huang et al, 2020; Hong et al, 2020; $\mathrm{Xu}$ and Tan, 2020), science and technology expenditure (Miao et al, 2017; Jin et al, 2019), foreign direct investment (Liu et al, 2018; Cheng et al, 2020), education investment ( $\mathrm{Li}$ et al, 2019), infrastructure construction (Huang et al, 2020), population agglomeration ( $\mathrm{Lv}$ and $\mathrm{Li}$, 2021; Chikaraishi et la, 2015) and other factors may have an impact on resource utilization efficiency. In addition, the flow of factors of production (such as captial, labor and technology) between cities may be manifested as the agglomeration of surrounding cities to central cities, that is, siphon effect (Wang et al,2019; Feng et al,2019). It may also be manifested in the central city through "technology spillover" to drive the high quality development of surrounding cities (Huang et al,2020). Finally, the efficiency of resources use between cities may shows heterogeneity or identity. In summary, based on the consideration of local and spatial factors, this paper employes spatial Durbin model to carry out an empirical research on the spatial correlation of GWUE and its influencing factors.

The rest of this paper is arranged as follows: the second chapter provides a literature review, the third chapter introduces DEA model and spatial econometric model, the fourth chapter conducts a result analysis, the fifth chapter discusses the empirical results, and the sixth chapter is conclusion and policy recommendations.

\section{Literature review}

Different samples have been used to investigate China's water efficiency or resource efficiency from existing studies. The research on provinces is the most abundant: Hong et al (2019) measures the water-energy bond efficiency of 30 provinces in China; Yao et al (2018) uses the four stage DEA model to measure the industrial water green total factor productivity of 30 provinces. In addition, Hu et al (2006); Long and Pijanowski (2017); Yan (2019); Geng et al (2019) and other scholars have conducted instructive research on water resource efficiency using provincial panel data. However, provincial data can not fully reflect the heterogeneity between cities, empirical conclusions may be biased. In order to more accurately assess the resources efficiency differences among cities, city-level data is widely used. Song et al (2020) explored the logistics land use efficiency of 113 cities in the Yangtze River economic belt; Guan et al (2019) measured the energy efficiency of 26 cities in the Yangtze River Delta and analyzed its influencing factors; Wang et al (2018) analyzed the urban carbon dioxide emission efficiency of 9 cities in the Pearl River Delta. However, so far, no scholars have measured the green water-use efficiency of cities in the Yellow River economic belt.

Stochastic Frontier Analysis (SFA) and Data Envelopment Analysis (DEA) methods are mainly used in the existing literature to measure resource efficiency. DEA, as a nonparametric method, has a greater advantage in dealing with multiple inputs and outputs. DEA method was first proposed by Charnes, Cooper and Rhodes in 1978, and has been developed for decades. Today, more than a hundred specific models and methods have been applied to 
empirical research. Among them, Malmquist method has the advantages of decomposing and discussing the specific driving factors and not assuming production function, so it is widely used in resource efficiency measurement. Yan (2019) calculated the Malmquist productivity index of agricultural water use efficiency in 31 provinces of China, and conclusiongs showed that the main reason for the decline of water efficiency was the technical retrogression. Mavi and Mavi (2019) used the Malmquist method to analyze the energy and environmental efficiency of OECD countries. Pastor and Lovell (2005) proposed the global Malmquist productivity index, which is the productivity index obtained from all sample points in the sample period as a reference set. This method solves the problem that there is no feasible solution under the assumption of VRS. An et al (2019) measured the environmental efficiency of the main stream and tributaries of the Xiangjiang River Basin by SBM method, and obtained the global Malmquist productivity index. Long et al (2020) estimated the global Malmquist productivity index of the logistics system of the Yangtze River economic belt, and analyzed the influencing factors by using the spatial econometric model. In addition, the research of Emrouznejab and Yang (2016), Du et al (2018), Wang et al (2020) and other scholars have also enriched the application of this method. However, we have not found any literature using global Malmquist method to measure the water-use efficiency of urban.

There are many valuable studies refer to the influence of economic and social factors on sustainable development or resource utilization efficiency. Xu and Tan (2020) proves that the increase in the proportion of secondary industry in the GDP has a negative impact on the efficiency of natural resource utilization, which mainly because the industrial development model dominated by heavy industry still dominates. In addition, industrial agglomeration also exacerbates increased pollutant emissions and leads to ecological degradation (Huang et al,2020; Hong et al,2020). Technological innovation is the main driving force of sustainable development, and it is also an important way to improve the efficiency of resource utilization (Li et al,2019). Miao et al (2017) using the stochastic frontier analysis method proved that the resource utilization efficiency shows a higher growth trend under the green technology innovation. Jin et al (2019) shown that technological innovation drives water efficiency, but there are significant regional differences. The impact of foreign direct investment on sustainable development of urban economy is reflected in the hypothesis of "pollution paradise" or "pollution halo", that is, whether foreign investment is due to pursuit of lower pollution costs. Empirical studies of China provinces or cities generally confirm the hypothesis environmental pollution and inhibits sustainable development or resource efficiency (Liu et al,2018; Cheng et al,2020). Population density has both positive and negative aspects on resource utilization. On the one hand, higher population density promotes higher energy consumption and environmental pollution. On the other hand, high population means higher level of human captial and higher potential for technological innovation (Lv and Li,2021; Chikaraishi et al, 2015). However, the existing studies have seldom considered the spatial correlation between cities. Liu and Lin (2019) shows that spatial econometric models can better evaluate the spatial effects of various factors on environmental quality or sustainabiltiy.

To sum up, the innovation of this paper is as follows: Firstly, the Green Water-Use Efficiency (GWUE) of 98 cities in the Yellow River Economic Belt (YREB) from 2005-2018 was measured for the first time. Secondly, for the first time, global Malmquist method 
including unexpected output and its decomposition index are used to measure urban water-use efficiency. Thirdly, the spatial correlation and its influencing factors of green water-use efficiency are analyzed empirically by using spatial Durbin model, and the economy-geography nested matrix is used in spatial regression.

\section{Method}

\subsection{Study Area}

The Yellow River flows through nine provinces in China (including: Shandong, Henan, Shanxi, Shannxi, Inner Mongolia, Ningxia, Gansu, Qinghai, Sichuan), is called "mother river" among Chinese, related to the livelihood of more than 400 million people and more than one third of the country's crops output, and is also an important bond of "One Belt, One Road" strategy in inland China (Wang et al,2012). Figure 1 shows the geographical location of the Yellow River Economic Belt (YREB) in China. YREB includes 118 cities, due to the lack of complete data, 20 cities are excluded (in white). Finally, we select 98 cities as samples for empirical study (in yellow).

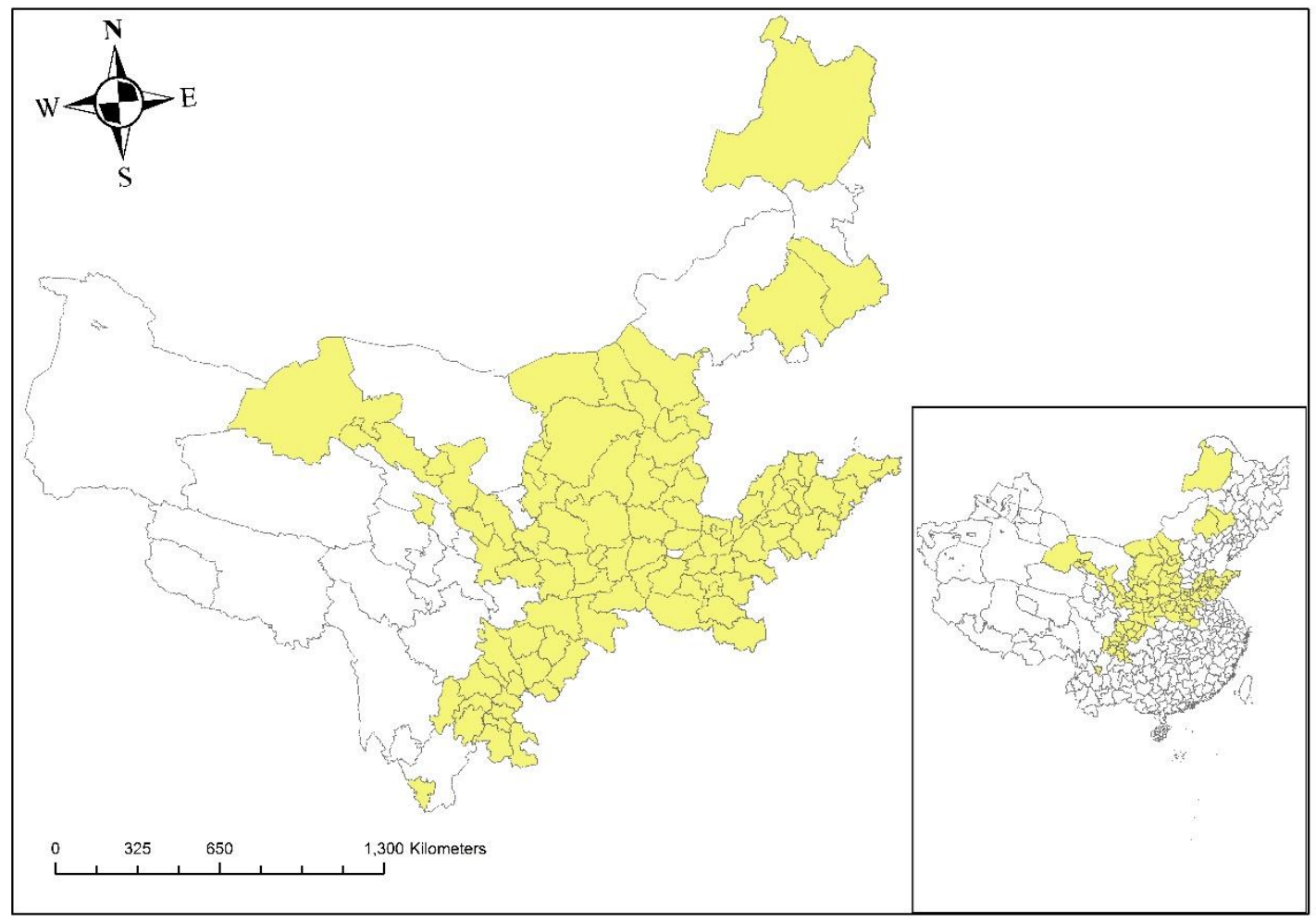

Fig.1 Yellow River Economic Belt

\subsection{DEA}

\subsubsection{Global Malmquist-Luenberger Productivity Index}

Malmquist productivity index is widely used to measure productive efficiency and has a major advantage in panel dataset. Fare et al (1992) calculated Malmquist Index (MI) with DEA method for the first time and decomposes it into two parts: one is the change of technical efficiency change (EC) between two periods; the other is the technology change (TC) between two periods, that is, the change of production frontier. $\mathrm{MI}=\mathrm{EC} * \mathrm{TC}$.

Fig.2 shows the theory of output-oriented Malmquist productivity index under the 
assumption of constant returns of scale (CRS). $\mathrm{X}$ represents input, $\mathrm{Y} 1$ and $\mathrm{Y} 2$ represent output (assume they are both desirable output). $\mathrm{A}^{1} \mathrm{~B}^{1} \mathrm{C}^{1}$ is the production frontier of period $t, \mathrm{~A}^{2} \mathrm{~B}^{2} \mathrm{C}^{2}$ is the production frontier of period $\mathrm{t}+1, \mathrm{~N}\left(\mathrm{x}^{\mathrm{n}}, \mathrm{y}^{\mathrm{n}}\right)$ and $\mathrm{M}\left(\mathrm{x}^{\mathrm{m}}, \mathrm{y}^{\mathrm{m}}\right)$ represent the productivity index of the DMU in period $t$ and $t+1$ respectively. Then Malmquist Productivity Index (MI) in the period from $t$ to $t+1$ is:

$$
M I\left(x^{m}, y^{m}, x^{n}, y^{n}\right)=\sqrt{\frac{E^{t}(M)}{E^{t}(N)} \frac{E^{t+1}(M)}{E^{t+1}(N)}}=\sqrt{\frac{E^{\mathrm{t}}\left(x^{m}, y^{m}\right)}{E^{t}\left(x^{n}, y^{n}\right)} \frac{E^{t+1}\left(x^{m}, y^{m}\right)}{E^{t+1}\left(x^{n}, y^{n}\right)}}
$$

$$
\text { In eq(1), } E^{t}(M)=E^{t}\left(x^{m} y^{m}\right)=\frac{O M^{1}}{O M} \text { is the productivity index that point } M \text { with }
$$

reference to production frontier $\mathrm{A}^{1} \mathrm{~B}^{1} \mathrm{C}^{1}$, The change with production frontier from $\mathrm{A}^{1} \mathrm{~B}^{1} \mathrm{C}^{1}$ to $\mathrm{A}^{2} \mathrm{~B}^{2} \mathrm{C}^{2}$ represent the technology change (TC) from period to $t+1$, could be measured by

$$
\frac{O N^{1}}{O N^{2}}=\frac{E^{t}\left(x^{n}, y^{n}\right)}{E^{t+1}\left(x^{n} y^{n}\right)} \text { and } \frac{O M^{1}}{O M^{2}}=\frac{E^{t}\left(x^{m}, y^{m}\right)}{E^{t+1}\left(x^{m}, y^{m}\right)} \text {, Fare et al (1992) measured the TC from } \mathrm{t}
$$

to $t+1$ with the following formula:

$$
T C=\sqrt{\frac{E^{t}\left(x^{n}, y^{n}\right)}{E^{t+1}\left(x^{n}, y^{n}\right)} \frac{E^{t}\left(x^{m}, y^{m}\right)}{E^{t+1}\left(x^{m}, y^{m}\right)}}
$$

$E^{t}\left(x^{n}, y^{n}\right)$ and $E^{\mathrm{t}+1}\left(x^{m}, y^{m}\right)$ represent the technical efficiency of the DMU in period $\mathrm{t}$ and $\mathrm{t}+1$ respectively, so the Technical Efficiency Change (EC) from $\mathrm{t}$ to $\mathrm{t}+1$ could be measured by the following formula:

$$
E C=\frac{E^{t+1}\left(x^{m}, y^{m}\right)}{E^{t}\left(x^{n}, y^{n}\right)}
$$

Under the assumption of variable returns to scale (VRS), the obtained technical efficiency value is pure pechnical efficiency value excluding scale effect. Thus the efficiency change under VRS is called Pure Technical Efficiency Change (PEC), and we can get Scale Efficiency Change (SEC) by the formula: EC=PEC*SEC.

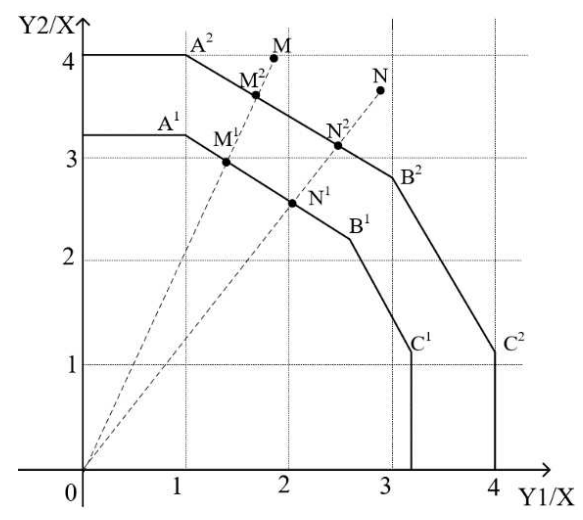

Fig 2. Output-oriented Malmquist productivity index

Fig.2 only reveals the theory of Malmquist productivity index in only two periods. When investigating multi-period panel dataset, scholars choose different reference production 
frontier to calculate Malmquist index, including fixed Malmquist; global Malmquist (Pastor and Lovell, 2005); sequential Malquist; window Malmquist. According to the different reference frontiers, Malmquist index has different characteristics and specific calculation methods. The global Malmquist method selected in this study is described below. The method in this paper refers to the study of Chung et al, (1997); Pastor and Loverll, (2005); Kumar and Managi, (2010); Emrouznejad and Yang, (2016); Kumar (2006). The software used in this study is MaxDEA8.0.

We take 98 cities in YREB as independent decision-making units (DMU), four variables as input indicators, named as $X=\left(x_{1}, x_{2}, x_{3}, x_{4}\right) \in R_{+}$, one variable as desirable output, named as $Y=(y) \in R_{+}$, one variable as undesirable output, named as $B=(b) \in R_{+}$, $\mathrm{t}=2007, \ldots, 2016$ is the research period of the study. The directional distance function defined in year $\mathrm{t}$ is as follows:

$$
D^{t}\left(x^{t}, y^{t}, b^{t}, g\right)=\max \left\{\beta \mid\left(y^{t}+\beta g_{y}, b^{t}-\beta g_{b}\right) \in p^{t}\left(x^{t}\right)\right\}
$$

In eq(4), $g=\left(g_{y}, g_{b}\right)$ is the directional vector, $\beta$ is the directional distance function of $y$ maximization and $b$ minimization in year $t$. The eq(4) shows that, given the input $X$, the expected output $\mathrm{Y}$ and the unexpected output B increase and decrease in the same proportion. $P^{t}\left(x^{t}\right)=\left\{\left(y^{t}, b^{t}\right) \mid x^{t} \Rightarrow\left(y^{t}, b^{t}\right)\right\}$ is the production possibility set of the current period. Global Mlamquist-Luenberger Productivity Index (GMLPI) represents the union of production possibility in all periods (2007 to 2016 in this study) as a global set of production possibility, that is, $P^{G}=P^{2007} \mathrm{U} P^{2008} \mathrm{U} \ldots \mathrm{U} P^{2016}$. Under Constant Returns to Scale (CRS) assumption, GMLPI from $\mathrm{t}$ to $\mathrm{t}+1$ can be defined as:

$$
\begin{aligned}
& \operatorname{GMLPI}^{t, t+1}\left(x^{t}, y^{t}, b^{t}, x^{t+1}, y^{t+1}, b^{t+1}\right)=\frac{1+D^{G}\left(x^{t}, y^{t}, b^{t}\right)}{1+D^{G}\left(x^{t+1}, y^{t+1}, b^{t+1}\right)} \\
& =\frac{1+D^{t}\left(x^{t}, y^{t}, b^{t}\right)}{1+D^{t+1}\left(x^{t+1}, y^{t+1}, b^{t+1}\right)} \times\left[\frac{1+D^{G}\left(x^{t}, y^{t}, b^{t}\right)}{1+D^{t}\left(x^{t}, y^{t}, b^{t}\right)} \times \frac{1+D^{t+1}\left(x^{t+1}, y^{t+1}, b^{t+1}\right)}{1+D^{G}\left(x^{t+1}, y^{t+1}, b^{t+1}\right)}\right] \\
& =E C_{t+1}^{t} \times T C_{t+1}^{t}
\end{aligned}
$$

In eq(5), $E C_{t+1}^{t}$ represents technical efficiency change from period t to $\mathrm{t}+1$, which means the city's production level and scale effect of science and technology. EC $>1$ reveals that there has been an improvement in efficiency between $t$ and $t+1 . T C_{t+1}^{t}$ represents the technological change from $t$ to $t+1$. TC $>1$ reveals the technical progress between $t$ and $t+1$. Under Variable Returns to Scale (VRS) assumption, we can get following formula:

$$
\operatorname{GMLPI}^{t, t+1}\left(x^{t}, y^{t}, b^{t}, x^{t+1}, y^{t+1}, b^{t+1}\right)=P E C_{t+1}^{t} \times P T C_{t+1}^{t}
$$

In eq(6), Pure Technical Efficiency Change (PEC) is the efficiency value obtained by eliminating the scale effect. Finally, GMLPI can be decomposed into 


\subsubsection{Input and output variables}

When measuring the Global Mlamquist-Luenberger Productivity Index (GMLPI), this paper takes capital, labor, water resources, technology expenditure as the input variable, and GDP and water pollutant emission as the output. The specific indicators are as follows:

Input: (1) Capital. Fixed asset investment refers to the capital invested by the economic entities in the purchase of plant and equipment, which is positively related to the actual capital investment level of the city. Therefore, according to Zhu et al (2019), we select the fixed asset investment of the whole society in the current year as the capital investment. (2) Labor. Due to the mobility of labor force and labor input varies in different periods, according to Zhu et al (2019) and Du et al (2018) this paper selects the number of urban employees at the end of the year to represent the labor input. (3) Water. It refers to the total quantity of water supplied by the water supply enterprise in the year, including effective water supply and loss or leakage, the users include agriculture, industry and services in the city.

Output: (4) GDP. Based on existing research (Wu et al,2018; Du et al,2018; Piao et al,2019), this paper selects the GDP of the city as the expected output. (5) Industrial waste water emission (wwater). It refers to the waste water and waste liquid after purification in the production process of industrial enterprises, which represents the negative impact on the water environment. This paper selects this indicator as undesirable output. The indicator can not reflect the impact of other social activities such as agriculture and service industry, but we think it can still be used to measure city water efficiency for the following reasons: Industrial waste water has a far-reaching impact on the environment due to heavy metal elements and higher requirements for cleaner production technology (Hao et al,2018; Liu et al,2014). The indicators come from "China Urban Statistical Yearbook 2008-2017" and "China Urban Construction Statistical Yearbook 2007-2016”.

\subsection{Spatial econometric model}

\subsubsection{SLM, SEM and SDM}

The First Law of Geography states that no city is isolated (Tobler, 1970). Existing studies have pointed out that spatial econometric model can avoid ignoring the spatial correlation among cities (Getis, 2007; Elhorst, 2003; Anselin, 2010). Water efficiency is not only affected by the variables of the local cith, but also may be affected by the "spillover effect" and "siphon effect" of the surrounding cities. Therefore, we employ the spatial econometrics model to investigate the spatial correlation of GMLPI and its determinants. The most widely used and relatively mature spatial econometric models are spatial lag model (SLM) and spatial error model (SEM) and spatial Durbin model (SDM). The SLM only considers the spatial correlation of the interpreted variable, while the explanatory variables only affect the interpreted variable in the city, but no spatial spillover effect (Ma et al,2016; Wang et al,2020b). SEM is considered to be a reasonable model when the error term has spatial correlation (Haining,1978; Casetti,1986; Wang et al,2020b). The SDM places both the interpreted and the explanatory variables into the spatial correlation analysis. The model urges that multiple variables have spatial effects on the surrounding areas, and multiple factors contribute to the variation of the interpreted variables (Ouedraogo,2016; Lv et al,2019). Combined with this studies, the SLM is set as follows: 
In eq(10), GMLPI represents the WGTFP of city in the YREB calculated based on DEA model introduced in the previous section. Because GMLPI shows a change in efficiency within two periods, this paper assumes that the GMLPI in 2007 is the base period, and transforms the GMLPI in the following years. X represents the control variable, and the specific calculation method and data source of each variable are discussed in the next section. W represents the spatial weight matrix established in this paper. $\rho$, spatial autoregressive coefficient of GMLPI, is the most concerned numerical value in this paper. $\beta$ and $\theta$

represents the explanatory variable parameter to be estimated, $\varepsilon_{i t}$ represents the error term.

SEM is set as follows:

$$
\left\{\begin{array}{l}
G M L P I_{i t}=\theta X_{i t}+\varepsilon_{i t} \\
\varepsilon_{i t}=\lambda W^{*} \varepsilon_{i t}+v_{i t}
\end{array}\right.
$$

In eq(11), the spatial correlation of error terms is the main factor different from other models. The meaning of each variable is the same as eq(11). Then, SDM is set as follows:

$$
G M L P I_{i t}=\rho \sum W^{*} G M L P I_{i t}+\gamma W * X_{i t}+\theta X_{i t}+\varepsilon_{i t}
$$

The meaning of each variable is the same as eq(11). The difference is that the SDM contains the spatial lag term of explanatory variables, which expressed by $\gamma$. It will analyze the spatial spillover effect of the explanatory variables. Elhorst (2014) proposed likehood ratio (LR) test method for SLM, SEM and SDM models, the test can identify whether the SDM could be simply reduced to the SEM or SLM.

\subsubsection{Spatial Weight Matrix}

The spatial weight matrix is used to measure the degree of interaction between cities. The larger the corresponding elements in the matrix, the higher the degree of interaction between the two cities. Most of the existing literature constructs weight matrix from two aspects: geographical factor or economic factor.

The theoretical basis for constructing a matrix based on geographical factor is that the closer the geographical distance between the two cities, the more advantages they have in raw material and commodity transportation, labor mobility, industrial production, etc (Wang et al,2019). Therefore, by constructing the geographic distance matrix (W1), this paper measures the actual spherical distance of the earth between cities, based on the longitude and latitude of each city, and it uses the reciprocal of the distance to represent the actual corresponding elements in Wgeo. There is no doubt that the closer the economic level between cities, the higher the degree of mutual influence (Bai et al,2012), thus the cities will tend to learn from cities with similar economic level, i.e. "imitation effect". This paper uses GDP per capita to measure the economic level of cities, and it takes the reciprocal of the absolute value of the difference between the annual average of GDP per capita for each city, in 2007-2016, to represent the elements of corresponding points, and then it constructs the economic distance matrix (Weco).

However, Wgeo and Weco can only analyze the spatial correlation under geographical or 
economic factors, in fact, in the real economic activities, both geographical and economic factors will play a significant role at the same time. Some scholars consider the combination of geographical matrix and economic matrix to alleviate the error in the setting of weight matrix (Shao et al,2019; Wang et al,2019). This paper constructs an economic-geographic nested matrix (WX), and it considers both geographical and economic factors, $\mathrm{WX}=0.5 *$ Wgeo $+0.5 *$ Weco.

\subsubsection{Variables and data sources}

Interpreted variable. Global Malmquist-Luenberger productivity index, GMLPI represents the green utilization efficiency of urban water resources. Furthermore, we decompose GMLPI into technical change (TC), pure technical efficiency change (PEC) and scale efficiency change (SEC), and take them as explanatory variables. This can help us to investigate the influence path of each explanatory variable on the Green Water Use Efficiency (GWUE).

Explanatory variables. (1) Industrial structure (TS). Industrial structure is widely used to analyze green economy in current research ( $\mathrm{Lv}$ and $\mathrm{Li}, 2021$; Huang et al,2020; Hong et al,2020; Xu and Tan,2020). The change of TS has two effects on the resource utilization efficiency. On the one hand, in the stage of urban inudstrial developing, the crude expansion mode makes the government put the economic benefits first, neglecting the sustainable development. At the same time, the deceloping of the TS will absorb the production factors of surrounding areas, namely the siphon effect, which makes negivate impacts to the sustainable development of surrounding cities and the local city. On the other hand, in the late stage of urban development, social expectations for environmental protection are getting higher, with the continuous improvement of cleaner production technology and emission reduction measures, public infrastructure construction plays a significant role, and the improvement of industrial structure contributes to improve the resource efficiency of the region, and at the same time, the spatial spillover effect will promote the improvement of production technology and efficiency in the neighboring areas. (2) Science and technology expenditure (TEC). Science and technology expenditure can promote the government and enterprises to strengthen the use of cleaner production technology, so as to promote technological progress (Miao et al,2017; Jin et al,2019). (3) Education expenditure (EDU). The education expenditure will affect the water efficiency by improving the quality of labor force and the scientific research ability ( $\mathrm{Li}$ et al,2019). (4) Foreign direct investment (FDI). The impact of FDI on sustainable development is reflected in the "pollution paradise" or "pollution halo" (Liu et al,2018; Cheng et al,2020), that is, whether foreign investment can promote resource efficiency by improving technology and management level, or bring more pollution to the city? (5) Investment in water supply and drainage facilities (INV). Infrastructure is an important means to reduce enterprise costs and improve economies of scale. This paper selects the level of government investment in water supply and drainage infrastructure to measure the impact of infrastructure on resource efficiency. (6) Population density (PEO). Population agglomeration may have both positive and negative effects on resource efficiency. According to Chikaraishi et al (2015) and $\mathrm{Lv}$ and $\mathrm{Li}$ (2021), we select urban population density to measure population agglomeration. The data of explanatory variables and control variables in the spatial econometric model are from "China Urban Statistical Yearbook 2008-2017" and "China Urban Construction Statistical Yearbook 2007-2016". The definitions and descriptive 
Table 1. Descirptive statistics of variables

\begin{tabular}{clccccc}
\hline Variable & \multicolumn{1}{c}{ Definition } & Obs & Mean & Std.Dev & Min & Max \\
\hline Capital & fixed asset investment of the whole society & 1372 & 1052.54 & 1075.75 & 36.01 & 8352.50 \\
Labor & number of urban employees & 1372 & 73.27 & 79.57 & 5.58 & 834.57 \\
Water supply & total quantity of water supplied by the water supply & 1372 & 8523.63 & 10965.85 & 397.54 & 111813.1 \\
& enterprise & & & & & \\
GDP & GDP of the city & 1372 & 1436.68 & 1468.16 & 61.84 & 12170.23 \\
wwater & industrial waste water emission & 1372 & 5438.16 & 4981.93 & 99.00 & 33007.00 \\
\hline GMLPI & global malmquist luenberger productivity index & 1274 & 109.70 & 19.27 & 84.94 & 214.98 \\
TC & technological change & 1274 & 106.87 & 29.51 & 49.15 & 235.65 \\
PEC & pure technical efficiency change & 1274 & 107.89 & 38.27 & 29.44 & 344.58 \\
SEC & scale efficiency change & 1274 & 104.54 & 21.24 & 44.50 & 276.40 \\
TS & proportion of added value of secondary industry in & 1274 & 51.46 & 11.13 & 18.79 & 84.39 \\
& GDP & & & & & 16.56 \\
TEC & proportion of science and technology expenditure in & 1274 & 1.04 & 0.87 & 0.06 & \\
& Finance & & & & & 37.74 \\
EDU & proportion of education expenditure in Finance & 1274 & 18.66 & 4.16 & 2.18 & 206.27 \\
FDI & (Logarithm of) foreign direct investment (dollar) & 1274 & 11.58 & 14.99 & 0.00 & 14.69 \\
INV & (Logarithm of) investment in water supply and & 1274 & 10.12 & 1.82 & 3.58 & \\
& drainage infrastructure & & & & & 5.62 \\
PEO & (Logarithm of) population per square kilometer & 1274 & 8.07 & 0.81 & 5.31 & \\
\hline
\end{tabular}

\section{Results}

\subsection{Green Water Use Efficiency of YREB}

Using the DEA model with unexpected output and the global Malmquist index method, this paper calculates the Green Water-Use Efficiency (GWUE) under the CRS and VRS assumptions, and obtains the Global Malmquist-Luenberger Productivity Index (GMLPI), and further decomposes GDMLPI into TC, PEC, SEC, that is, GMLPI = TC * SEC* PEC

Figure 3 shows the average of GMLPI and its decomposition terms between 2005-2018. First of all, the GMLPI of each year in the sample period is greater than 1, with an average annual value of 1.0786, which means that the GWUE of the YREBt increases by about $7.86 \%$ annually. This shows that the YREB performs well in the sustainable development of water resources in the period. Environmental regulation and cleaner production improve the water use efficiency of the government and enterprises. This caters to the sustainable development goal of "from quantity driven to high quality development". After decomposing GMLPI into TC, PEC and SEC, we found that all higher value of the three indicators contribute to higher GMLPI. The average values of TC, PEC and SEC were 1.0257, 1.0384 and 1.0187 respectively, which means that the average annual progress was about $2.57 \%, 3.84 \%$ and $1.87 \%$ respectively. The driving effect of PEC on GWUE is the most obvious. PEC represents the management level of government and enterprises in water use and the utilization efficiency of existing technologies. Therefore, strengthening environmental regulation and improving management level are still important means to promote GWUE in the future. Technological Change (TC) represents the development of new cleaner production technology and emission reduction technology. Technological progress is also an 
important factor to promote the progress of GWUE in the period between 2005 to 2018. The progress of scale efficiency also promotes GWUE, but its effect is lower than that of technical progress and pure technical efficiency. The annual average value of SEC is greater than 1, which indicates that the cities are in the stage of increasing returns to scale. Expanding the scale of water resources production can further improve the utilization efficiency.

However, although TC, PEC and SEC showed an upward trend, they fluctuated greatly. TC was less than 1 in 2007, 2011, 2013 and 2016 (respectively 0.9245, 0.9714, 0.9537, 0.9342), showing a significant technical regression. Similarly, PEC and SEC also showed sharp fluctuations over the years. This shows that GWUE lacks the motivation to make steady progress. It should be the common goal of the government and enterprises in the future to promote the steady improvement of technological progress and technical efficiency, and make it a stable driving factor to promote the sustainable development of water.

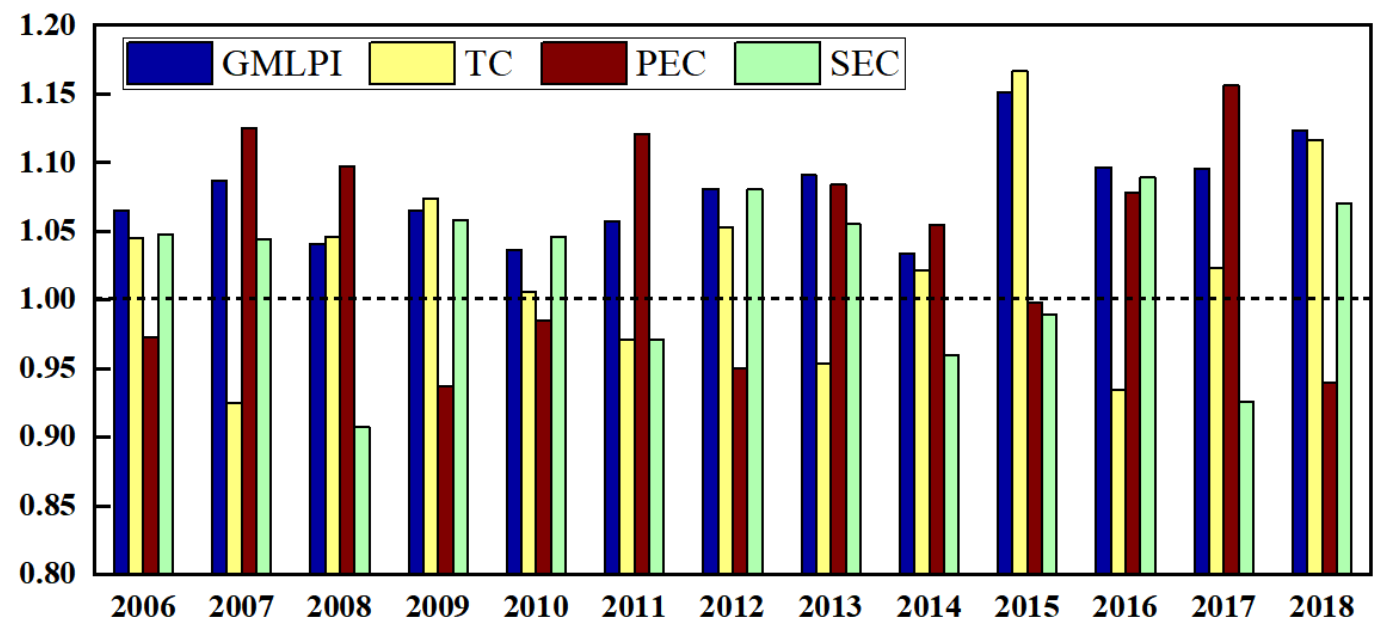

Fig.3 Trend of GMLPI and its decomposition index of YREB between 2006-2018

Next, we analyze the spatial distribution characteristics of GWUE in the YREB. Figure 4 shows the GMLPI, TC, PEC, SEC of 98 cities in 2007 and 2018. We can find the following three characteristics from the figure:

Firstly, GMLPI and its decomposition index fluctuate widely. Taking 2007 as an example, the highest and lowest values of TC were 1.2354 and 0.5883 ; the highest and lowest values of PEC were 1.8822 and 0.5188 ; the highest and lowest values of sec were 1.8755 and 0.5661 , respectively. The other years also show the same characteristics, which shows that the urban green water resources utilization efficiency lacks stable growth momentum. Secondly, the driving effect of technological progress on gwue is more and more obvious during the period. Figure 4-b shows that in 2007, only 24 cities have made technological progress (i.e., TC > 1), but in 2018 (Figure 4-f), 88 cities have made technological progress. This shows that technological progress is gradually becoming an important driving factor of GWUE. Finally, the cities present obvious "high-high" or "low-low" spatial correlation characteristics, that is, a city may be affected by the same direction of the surrounding cities. This reminds the government to strengthen cooperation and exchange with surrounding cities to improving the efficiency of resource utilization. 

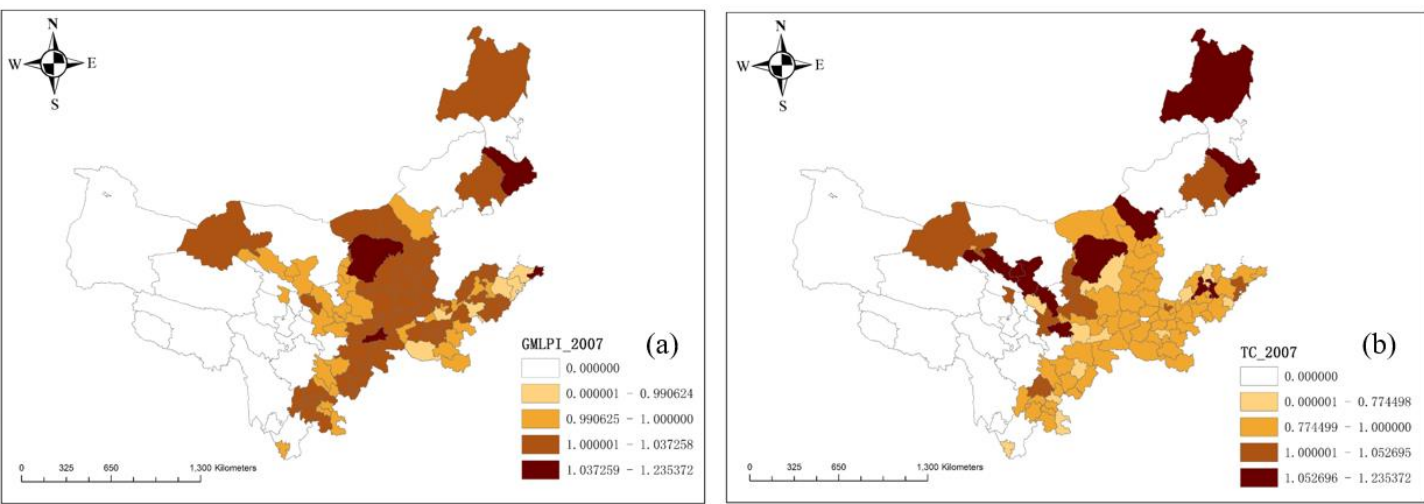

431
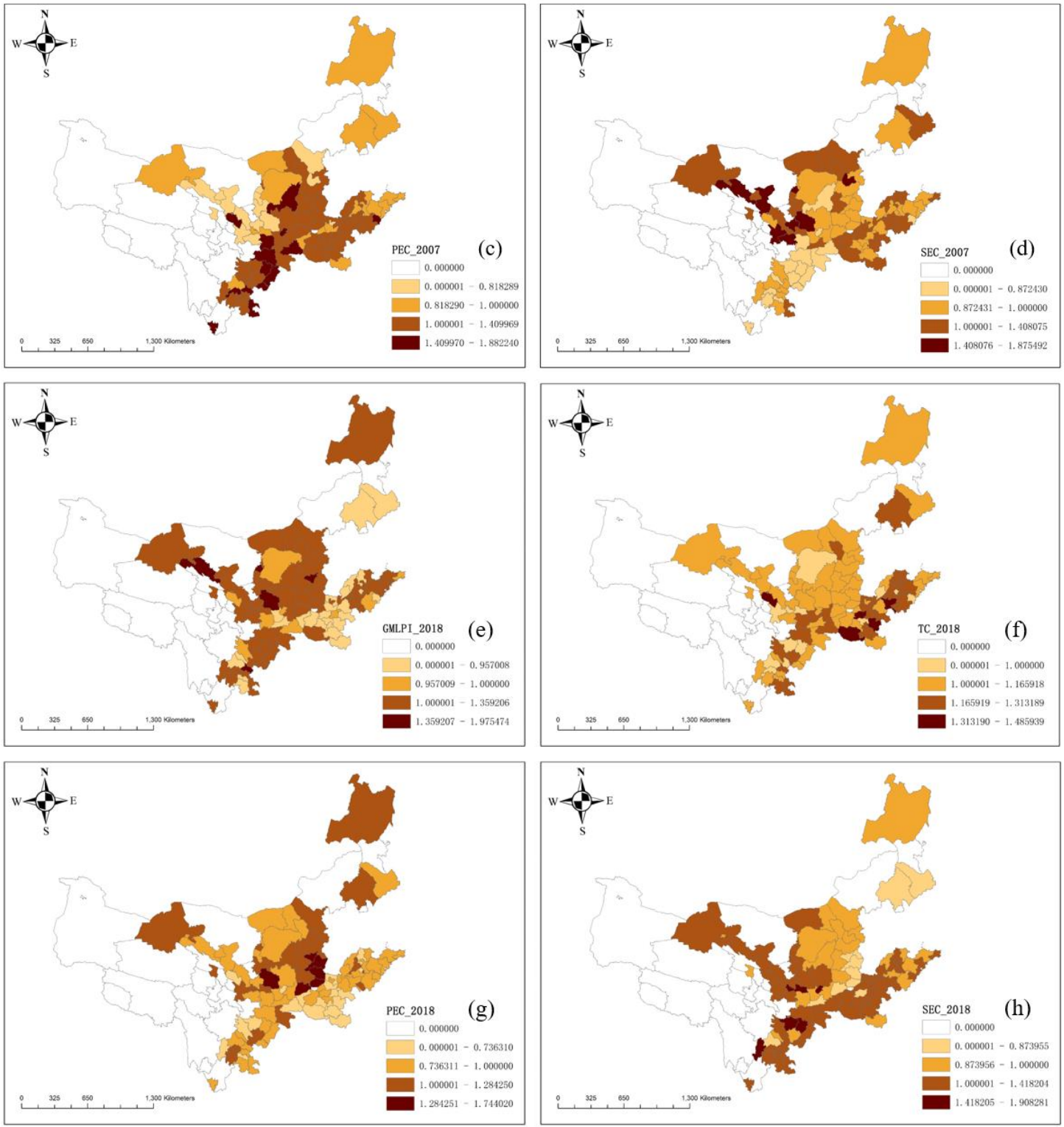

Fig.4 Spatial distrubution of GWUE in 2007 and 2018.

\subsection{Result of econometric models}

\subsubsection{Results without spatial interaction effects}

Before the spatial analysis, it is necessary to use the model without spatial factors to 
438 and model test results of each panel regression model. From left to right, OLS mixed regression

439 model, random effect model, individual fixed effect model, time fixed effect model and two-way

440 fixed effect model were used. The results of F test, LM Test, Hausman test and joint significance

441 test of year dummy variables show that the two-way fixed model is the optimal model. The

442 regression result show that the regression coefficients of TS, TEC and EDU are positive and

443 statistically significant. An increase of $1 \%$ in the proportion of the secondary industry will

444 contribute to a higher GWUE by about $0.298 \%$; the increase of science and technology

445 expenditure and education expenditure by 1\% will lead to the arise of GWUE by about $0.664 \%$

446 and $0.447 \%$, respectively. On the contrary, a $1 \%$ increase in FDI will lead to a decrease of about

$447 \quad 0.087 \%$ in GWUE.

448

Table 2. Estimation results without spatial interation effects

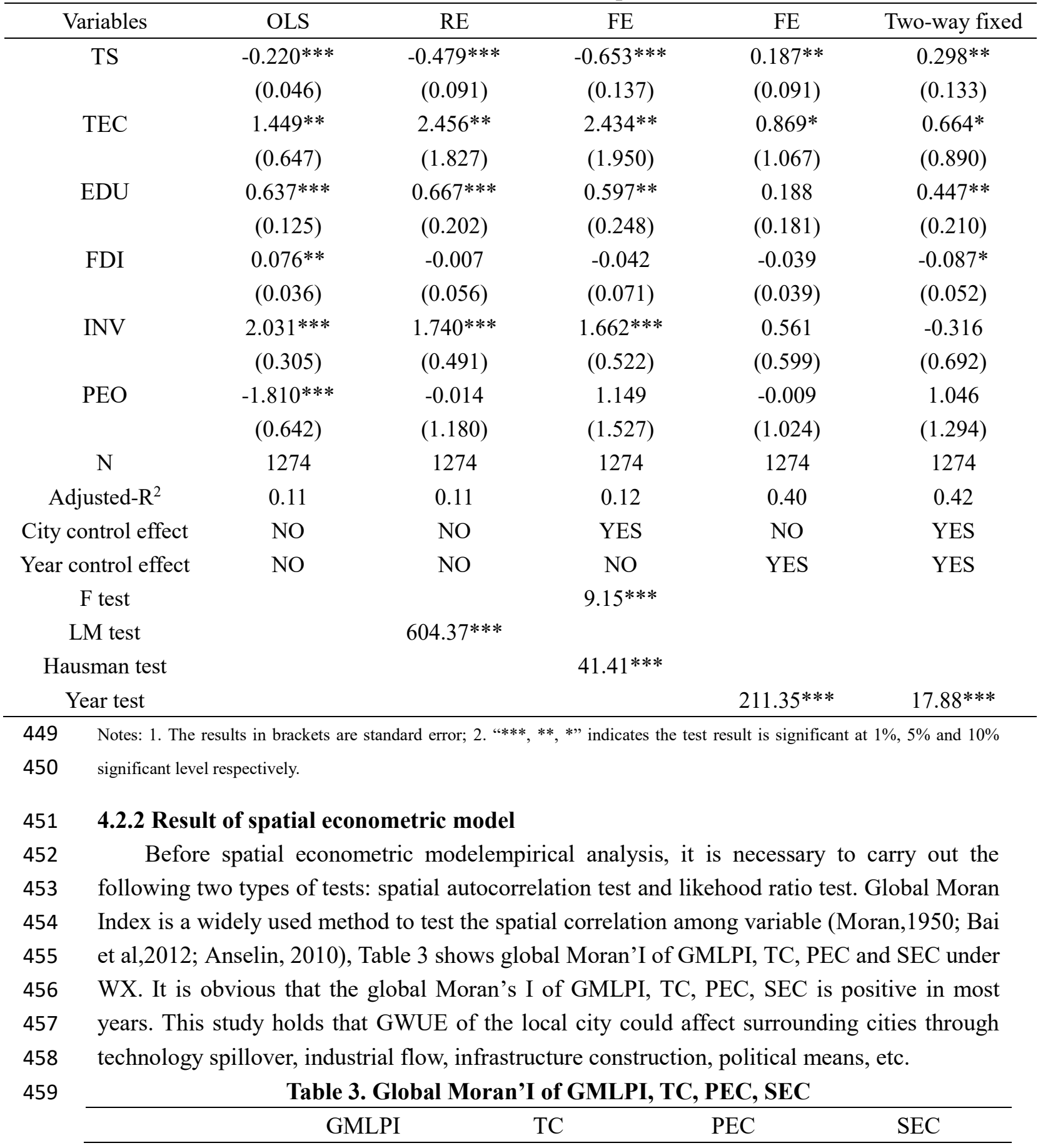




\begin{tabular}{lcccc}
\hline 2006 & $0.076^{* *}$ & $0.065^{*}$ & -0.003 & $0.058^{* *}$ \\
2007 & 0.012 & 0.010 & $0.084^{* * *}$ & $0.059^{* * *}$ \\
2008 & 0.001 & $0.047^{* * *}$ & $0.089^{* * *}$ & $0.061^{* * *}$ \\
2009 & $0.033^{*}$ & $0.060^{* * *}$ & $0.035^{* *}$ & $0.062^{* * *}$ \\
2010 & $0.052^{* *}$ & $0.035^{* *}$ & $0.068^{* * *}$ & $0.050^{* *}$ \\
2011 & $0.071^{* *}$ & $0.062^{* *}$ & $0.055^{* *}$ & $0.048^{* *}$ \\
2012 & $0.108^{* * *}$ & $0.041^{* *}$ & $0.029^{*}$ & $0.070^{* *}$ \\
2013 & $0.091^{* * *}$ & $0.180^{* * *}$ & $0.189^{* * *}$ & $0.041^{* *}$ \\
2014 & $0.087^{* * *}$ & $0.126^{* * *}$ & $0.123^{* * *}$ & $0.027^{*}$ \\
2015 & $0.099^{* * *}$ & $0.055^{* * *}$ & $0.037^{* *}$ & $0.090^{* * *}$ \\
2016 & $0.105^{* * *}$ & $0.059^{* * *}$ & $0.088^{* * *}$ & $0.110^{* * *}$ \\
2017 & $0.133^{* * *}$ & $0.076^{* * *}$ & $0.037^{* *}$ & 0.016 \\
2018 & $0.089^{* * *}$ & $0.129^{* * *}$ & 0.003 & $0.049^{* *}$ \\
\hline
\end{tabular}

460

461

462

463

464

465

466

467

468

469

470

471

472

473

474

475

Note: “***, **, *" indicates the result is significant at $1 \%, 5 \%$ and $10 \%$ significant level respectively.

Furthermore, local Moran index is used to identify the local spatial correlation among variable. Figure 5 shows the local Moran's I scatter map of GMLPI, TC, PEC and SEC of 98 cities in the YREB in 2016. The results find that GMLPI, TC, PEC, SEC are characterized by "high-high" or "low-low".
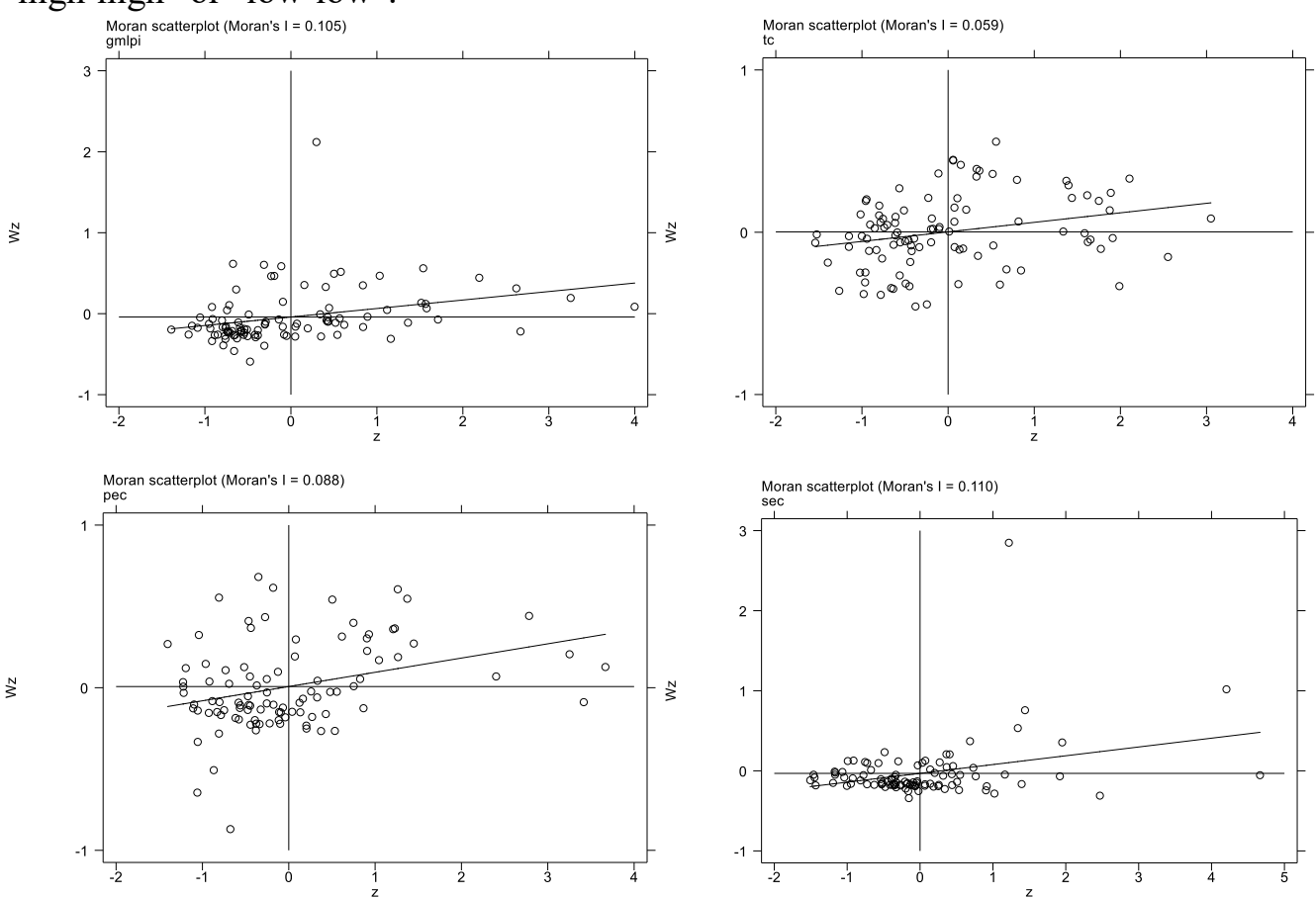

Fig 5. Moran's I scatter map of GMLPI

Table 4 reports the regression results of the spatial econometric model with GMLPI as the explanatory variable. The LR test results show that SDM is the optimal model regardless of the spatial weight matrix. Since the matrix WX considers the influence of economic factors and geographical factors. Therefore, this section will mainly discuss the SDM regression results based on the matrix WX.

Firstly, the spatial lag coefficient of GMLPI is positive and significant at the level of $1 \%$. The $1 \%$ rise in the GMLPI in the surrounding cities will lead to an increase of $0.321 \%$ in the local city. It indicates that the improvement of water efficiency in surrounding cities also 
promotes the sustainable development of water resources in the local city, which may be due to the "technology spillover effect" and "political competition" occupying the dominant position. The technological progress and environmental protection achievements of the surrounding cities will stimulate the environment-friendly development of the local city. Secondly, among the other explanatory variables, TS and EDU have positive effects on the local city and significantly. Every 1\% increase in TS and EDU will promote the GWUE by about $0.498 \%$ and $0.225 \%$ respectively, implying that industrial agglomeration and education expenditure will significantly improve the water resources efficiency of YREB. In addition, the coefficients of TEC, INV and PEO are also positive but unsignificantly, which indicates that increasing science and technology expenditure, strengthening water supply and drainage infrastructure, and increasing population density have positive effects on GWUE of the local city. The spatial lag coefficients of TS and FDI are negative and significant at $1 \%$ level. Every $1 \%$ increase in the TS and FDI in surrounding cities will lead to the decline of GWUE by $1.003 \%$ and $0.486 \%$ respectively. This may be because the industrial development and foreign investment in surrounding cities have a more significant "siphon effect" on the local city, which weakening the water sustainable development ability. In addition, the spatial lag coefficient of PEO is positive and significant at the level of $10 \%$. The increase of population density in surrounding cities by $1 \%$ will lead to the improvement of water resource efficiency by about $4.9 \%$.

\begin{tabular}{cccccc}
\hline Variables & SLM(WX) & SEM(WX) & SDM(Wgeo $)$ & SDM(Weco) & SDM(WX) \\
\hline W*GMLPI & $0.376^{* * *}$ & $0.399^{* * *}$ & $0.536^{* * *}$ & $0.148^{* * *}$ & $0.321^{* * *}$ \\
& $(0.066)$ & $(0.066)$ & $(0.064)$ & $(0.054)$ & $(0.068)$ \\
TS & $0.321^{* * *}$ & $0.380^{* * *}$ & $0.376^{* * *}$ & $0.444^{* * *}$ & $0.498^{* * *}$ \\
& $(0.069)$ & $(0.073)$ & $(0.077)$ & $(0.073)$ & $(0.074)$ \\
TEC & 0.560 & 0.441 & 0.522 & 0.254 & 0.176 \\
& $(0.558)$ & $(0.558)$ & $(0.548)$ & $(0.557)$ & $(0.552)$ \\
EDU & $0.398^{* * *}$ & $0.355^{* *}$ & $0.418^{* * *}$ & $0.245^{* *}$ & $0.225^{* *}$ \\
& $(0.152)$ & $(0.156)$ & $(0.164)$ & $(0.154)$ & $(0.156)$ \\
FDI & $-0.071^{* *}$ & -0.059 & -0.035 & -0.055 & -0.046 \\
& $(0.036)$ & $(0.036)$ & $(0.036)$ & $(0.036)$ & $(0.036)$ \\
INV & -0.292 & -0.213 & -0.127 & 0.077 & 0.048 \\
& $(0.413)$ & $(0.412)$ & $(0.404)$ & $(0.420)$ & $(0.415)$ \\
PEO & 0.911 & 0.746 & $1.260^{*}$ & 0.315 & 0.313 \\
& $(0.781)$ & $(0.782)$ & $(0.767)$ & $(0.786)$ & $(0.778)$ \\
W*TS & - & - & $-0.560^{* * *}$ & $-0.778^{* * *}$ & $-1.003^{* * *}$ \\
& & & $(0.206)$ & $(0.180)$ & $(0.232)$ \\
W*TEC & - & - & -3.002 & 2.470 & 2.591 \\
& & & $(3.020)$ & $(1.649)$ & $(2.257)$ \\
W*EDU & - & - & 0.570 & 0.658 & 0.731 \\
& - & $-0.803^{* * *}$ & $-0.282^{* *}$ & $-0.486^{* * *}$ \\
W*FDI & - & $-5.725^{* * *}$ & 0.921 & $(0.155)$ \\
& - & & & & 0.532 \\
\hline W*INV & - & & $(0.604)$ & $(0.438)$ &
\end{tabular}




\begin{tabular}{|c|c|c|c|c|c|c|}
\hline \multirow{3}{*}{\multicolumn{2}{|c|}{$\mathrm{W}^{*} \mathrm{PEO}$}} & \multirow{3}{*}{-} & & $(2.102)$ & $(1.165)$ & $(1.558)$ \\
\hline & & & & 2.274 & $5.048^{* *}$ & $4.900^{*}$ \\
\hline & & & & $(5.207)$ & $(2.401)$ & $(3.266)$ \\
\hline & $\mathrm{N}$ & 1274 & 1274 & 1274 & 1274 & 1274 \\
\hline & $\mathrm{R}^{2}$ & 0.12 & 0.09 & 0.33 & 0.36 & 0.38 \\
\hline & Two-way fixed & YES & YES & YES & YES & YES \\
\hline & LR test for SAR & - & - & $36.27 * * *$ & $46.66 * * *$ & $49.14 * * *$ \\
\hline & LR test for SEM & - & - & $33.09 * * *$ & $45.22 * * *$ & $46.03 * * *$ \\
\hline 496 & \multirow{2}{*}{\multicolumn{6}{|c|}{ Notes: 1 . The results in brackets are standard error; 2. “***, **, *" indicates the result is significant at $1 \%, 5 \%$ and $10 \%$}} \\
\hline 497 & \multicolumn{5}{|c|}{ significant level respectively. } & \\
\hline 498 & \multicolumn{6}{|c|}{ orts the regression results of the spatial econ } \\
\hline 499 & \multicolumn{6}{|c|}{ explanatory variable. Firstly, the spatial lag coefficient of TC is positive and significant at $1 \%$, } \\
\hline 500 & \multicolumn{6}{|c|}{ indicating the increase of technical progress of surrounding cities by $1 \%$ will contribute the } \\
\hline 501 & \multirow{2}{*}{\multicolumn{6}{|c|}{$\begin{array}{l}\text { TC of the local city by } 0.393 \% \text {. This proves the existence of technology spillover effect. This } \\
\text { enlightens us that the cooperation between cities in science and technology can achieve }\end{array}$}} \\
\hline 502 & & & & & & \\
\hline 503 & \multirow{2}{*}{\multicolumn{6}{|c|}{$\begin{array}{l}\text { win-win situation and promote the sustainable development of both sides. The coefficients of } \\
\text { TEC, EDU and PEO are positive and significant. Every } 1 \% \text { increase in TEC, EDU and PEO }\end{array}$}} \\
\hline 504 & & & & & & \\
\hline 505 & \multicolumn{6}{|c|}{ will contribute to TC of the local city by $2.206 \%, 0.771 \%$ and $3.265 \%$ respectively. This } \\
\hline 506 & \multicolumn{6}{|c|}{ shows that higher expenditure on science and technology and education can improve the level } \\
\hline 507 & \multicolumn{6}{|c|}{ of scientific and technological innovation and promote technological progress. The significant } \\
\hline 508 & \multicolumn{6}{|c|}{ impact of population density on technological progress may be due to that city with higher } \\
\hline 509 & \multicolumn{6}{|c|}{ population density have more advantages in talent reserve and $R \& D$ personnel, which is more } \\
\hline 510 & \multicolumn{6}{|c|}{ conducive to urban technological innovation. The spatial lag coefficients of TS, FDI and INV } \\
\hline 511 & \multirow{2}{*}{\multicolumn{6}{|c|}{$\begin{array}{l}\text { are negative and statistically significant. The increase of TS, FDI and INV in surrounding } \\
\text { cities by } 1 \% \text { will lead to the decrease of TC in the local city by } 1.572 \%, 0.320 \% \text { and } 4.275 \%\end{array}$}} \\
\hline 512 & & & & & & \\
\hline 513 & \multirow{5}{*}{\multicolumn{6}{|c|}{$\begin{array}{l}\text { respectively. On the contrary, the spatial lag coefficient of EDU is significantly positive, } \\
\text { means the increase of education expenditure in surrounding cities by } 1 \% \text { will promote the } \\
\text { technological progress of the local city by } 0.934 \% \text {. Indicates that the education expenditure of } \\
\text { the city may improve the technical level of water resources utilization in the surrounding } \\
\text { cities through the flow of talents and technology spillover. }\end{array}$}} \\
\hline 514 & & & & & & \\
\hline 515 & & & & & & \\
\hline 516 & & & & & & \\
\hline 517 & & & & & & \\
\hline \multirow[t]{2}{*}{518} & \multicolumn{6}{|c|}{ Table 5. Empirical results of spatial Durbin model (TC) } \\
\hline & Variables & SLM(WX) & $\operatorname{SEM}(\mathrm{WX})$ & SDM(Wgeo $)$ & $\operatorname{SDM}(W e c o)$ & $\mathrm{SDM}(\mathrm{WX})$ \\
\hline \multirow{2}{*}{\multicolumn{2}{|c|}{$\mathrm{W} * \mathrm{TC}$}} & $0.179 * * *$ & 0.090 & $0.545 * * *$ & $0.192 * * *$ & $0.393 * * *$ \\
\hline & & $(0.066)$ & $(0.075)$ & $(0.068)$ & $(0.045)$ & $(0.053)$ \\
\hline & TS & $-0.453 * * *$ & $-0.472 * * *$ & $-0.290 * * *$ & $-0.290 * * *$ & $-0.176^{*}$ \\
\hline & & $(0.097)$ & $(0.100)$ & $(0.106)$ & $(0.098)$ & $(0.102)$ \\
\hline & TEC & $2.707 * * *$ & $2.757 * * *$ & $2.788 * * *$ & $2.097 * * *$ & $2.206^{* * *}$ \\
\hline & & $(0.771)$ & $(0.774)$ & $(0.753)$ & $(0.756)$ & $(0.758)$ \\
\hline & EDU & $0.839 * * *$ & $0.856^{* * *}$ & $0.994 * * *$ & $0.697 * * *$ & $0.771 * * *$ \\
\hline & & $(0.211)$ & $(0.213)$ & $(0.226)$ & $(0.209)$ & $(0.214)$ \\
\hline & FDI & $-0.155^{* * *}$ & $-0.158 * * *$ & $-0.172 * * *$ & $-0.119 * *$ & $-0.119 * *$ \\
\hline & & $(0.050)$ & $(0.050)$ & $(0.049)$ & $(0.049)$ & $(0.049)$ \\
\hline & INV & $-1.501 * * *$ & $-1.530 * * *$ & $-1.315^{* *}$ & $-1.213 * *$ & $-1.178 * *$ \\
\hline & & $(0.573)$ & $(0.578)$ & $(0.555)$ & $(0.570)$ & $(0.570)$ \\
\hline
\end{tabular}




\begin{tabular}{|c|c|c|c|c|c|}
\hline PEO & $\begin{array}{c}3.850 * * * \\
(1.084)\end{array}$ & $\begin{array}{c}3.888 * * * \\
(1.100)\end{array}$ & $\begin{array}{c}3.816^{* * *} \\
(1.054)\end{array}$ & $\begin{array}{c}3.482 * * * \\
(1.068)\end{array}$ & $\begin{array}{c}3.265^{* * *} \\
(1.070)\end{array}$ \\
\hline $\mathrm{W}^{*} \mathrm{TS}$ & - & - & $\begin{array}{l}-0.380 \\
(0.288)\end{array}$ & $\begin{array}{c}-1.209 * * * \\
(0.246)\end{array}$ & $\begin{array}{c}-1.572 * * * \\
(0.322)\end{array}$ \\
\hline $\mathrm{W}^{*} \mathrm{TEC}$ & - & - & $\begin{array}{c}2.962 \\
(4.141)\end{array}$ & $\begin{array}{c}2.261 \\
(2.243)\end{array}$ & $\begin{array}{l}3.993 * \\
(3.104)\end{array}$ \\
\hline $\mathrm{W}^{*} \mathrm{EDU}$ & - & - & $\begin{array}{c}0.326 \\
(0.829)\end{array}$ & $\begin{array}{l}1.061^{*} \\
(0.596)\end{array}$ & $\begin{array}{l}0.934 * \\
(0.801)\end{array}$ \\
\hline $\mathrm{W}^{*} \mathrm{FDI}$ & - & - & $\begin{array}{c}0.119 \\
(0.280)\end{array}$ & $\begin{array}{c}-0.319 * * \\
(0.155)\end{array}$ & $\begin{array}{c}-0.320 * * \\
(0.213)\end{array}$ \\
\hline $\mathrm{W} * \mathrm{INV}$ & - & - & $\begin{array}{c}-6.364 * * \\
(2.919)\end{array}$ & $\begin{array}{l}-2.514 \\
(1.587)\end{array}$ & $\begin{array}{c}-4.275^{* *} \\
(2.150)\end{array}$ \\
\hline $\mathrm{W}^{*} \mathrm{PEO}$ & - & - & $\begin{array}{c}3.245 \\
(7.158)\end{array}$ & $\begin{array}{c}17.756^{* * *} \\
(3.309)\end{array}$ & $\begin{array}{c}21.360 * * * \\
(4.554)\end{array}$ \\
\hline $\mathrm{N}$ & 1274 & 1274 & 1274 & 1274 & 1274 \\
\hline $\mathrm{R}^{2}$ & 0.15 & 0.10 & 0.18 & 0.20 & 0.20 \\
\hline Two-way fixed & YES & YES & YES & YES & YES \\
\hline LR test for SAR & - & - & $10.98 *$ & $76.62 * * *$ & $71.12 * * *$ \\
\hline LR test for SEM & - & - & $18.10^{* * *}$ & $75.30 * * *$ & $76.82 * * *$ \\
\hline
\end{tabular}

519 Table 6 reports the regression results of spatial econometric model with pure technical

520 efficiency (PEC) as the explanatory variable. Firstly, the spatial lag coefficient of PEC is

521 positive and significant at the level of $1 \%$. The increase of PEC in surrounding cities by $1 \%$

522 will lead to a $0.244 \%$ increase of the local city. This shows that the improvement of

523 management level and utilization level of existing technologies in surrounding cities will also

524 promote the pure technical efficiency of the city. The coefficients of TS and INV are

525 significantly positive, the increase of the TS and INV by $1 \%$ will increase the pure technical

526 efficiency of the city by $0.856 \%$ and $2.135 \%$, respectively. Conversely, the coefficients of

527 TEC and EDU are significantly negative. The increase of TEC and EDU by $1 \%$ will lead to

528 the decrease of PEC by $2.97 \%$ and $0.81 \%$ respectively. In the spatial regression results of

529 variables, the coefficient of TEC is significantly positive. The increase of $1 \%$ in science and

530 technology expenditure of surrounding cities will promote the pure technical efficiency of the

531 city by $4.872 \%$. In addition, the spatial lag coefficients of TS, INV and PEO are significantly

532 negative. The increase of TS, INV and PEO in surrounding cities by $1 \%$ will lead to the

533 decrease of pure technical efficiency of the local city by $1.085 \%, 2.085 \%$ and $12.936 \%$

534 respectively.

535 Table 6. Empirical results of spatial Durbin model (PEC)

\begin{tabular}{cccccc}
\hline Variables & SLM(WX) & SEM(WX) & SDM(Wgeo) & SDM(Weco) & SDM(WX) \\
\hline W*PEC & $0.367^{* * *}$ & $0.410^{* * *}$ & $0.582^{* * *}$ & 0.077 & $0.244^{* * *}$ \\
& $(0.060)$ & $(0.060)$ & $(0.070)$ & $(0.052)$ & $(0.065)$ \\
TS & $0.888^{* * *}$ & $0.502^{* * *}$ & $0.712^{* * *}$ & $0.779^{* * *}$ & $0.856^{* * *}$ \\
& $(0.153)$ & $(0.156)$ & $(0.171)$ & $(0.159)$ & $(0.168)$ \\
TEC & $-2.758^{* *}$ & $-2.341^{*}$ & $-2.684^{* *}$ & $-2.539^{* *}$ & $-2.970^{* *}$ \\
& $(1.240)$ & $(1.262)$ & $(1.217)$ & $(1.243)$ & $(1.247)$ \\
EDU & $-0.787^{* *}$ & $-0.969^{* * *}$ & $-0.804^{* *}$ & $-0.847^{* *}$ & $-0.810^{* *}$ \\
\hline
\end{tabular}




\begin{tabular}{|c|c|c|c|c|c|}
\hline & $(0.339)$ & $(0.338)$ & $(0.364)$ & $(0.343)$ & $(0.355)$ \\
\hline \multirow[t]{2}{*}{ FDI } & 0.074 & 0.076 & 0.063 & 0.086 & 0.079 \\
\hline & $(0.080)$ & $(0.081)$ & $(0.079)$ & $(0.081)$ & $(0.081)$ \\
\hline \multirow[t]{2}{*}{ INV } & 1.384 & $1.661 * *$ & $1.432 *$ & $2.219 * *$ & $2.135^{* *}$ \\
\hline & $(0.919)$ & $(0.722)$ & $(0.897)$ & $(0.090)$ & $(0.911)$ \\
\hline \multirow[t]{2}{*}{ PEO } & -2.557 & -1.688 & -1.947 & -2.403 & -1.981 \\
\hline & (1.738) & $(1.781)$ & (1.704) & $(1.780)$ & (1.766) \\
\hline \multirow[t]{2}{*}{$\mathrm{W}^{*} \mathrm{TS}$} & - & - & -0.260 & $-1.040^{* * *}$ & $-1.085^{* * *}$ \\
\hline & & & $(0.466)$ & $(0.244)$ & $(0.286)$ \\
\hline \multirow[t]{2}{*}{$\mathrm{W} *$ TEC } & - & - & -2.857 & $4.270 * * *$ & $4.872 * * *$ \\
\hline & & & (6.709) & $(2.811)$ & $(3.279)$ \\
\hline \multirow[t]{2}{*}{$\mathrm{W}^{*} \mathrm{EDU}$} & - & - & -0.249 & $-1.227 * *$ & -0.970 \\
\hline & & & $(1.342)$ & $(0.628)$ & $(0.746)$ \\
\hline \multirow[t]{2}{*}{$\mathrm{W} * \mathrm{FDI}$} & - & - & 0.401 & 0.133 & 0.208 \\
\hline & & & $(0.452)$ & $(0.244)$ & $(0.314)$ \\
\hline \multirow[t]{2}{*}{$\mathrm{W}^{*} \mathrm{INV}$} & - & - & 0.537 & $-1.791^{*}$ & $-2.085^{*}$ \\
\hline & & & (4.657) & (1.094) & (1.139) \\
\hline \multirow[t]{2}{*}{$\mathrm{W}^{*} \mathrm{PEO}$} & - & - & $-22.145^{* *}$ & $-8.801 *$ & $-12.936^{*}$ \\
\hline & & & $(11.575)$ & $(5.253)$ & $(6.940)$ \\
\hline $\mathrm{N}$ & 1274 & 1274 & 1274 & 1274 & 1274 \\
\hline $\mathrm{R}^{2}$ & 0.04 & 0.05 & 0.11 & 0.11 & 0.12 \\
\hline Two-way fixed & YES & YES & YES & YES & YES \\
\hline LR test for SAR & - & - & 4.67 & $13.88^{* *}$ & $13.85^{* *}$ \\
\hline LR test for SEM & - & - & 6.93 & $13.85^{* *}$ & $13.91 * *$ \\
\hline \multirow{10}{*}{\multicolumn{6}{|c|}{$\begin{array}{l}\text { Table } 7 \text { reports the regression results of spatial econometric model with the scale } \\
\text { efficiency change (SEC) as the explanatory variable. The spatial lag coefficient of SEC is } \\
\text { positive and significant at the level of } 1 \% \text {. A } 1 \% \text { increase in the scale efficiency of } \\
\text { surrounding cities will promote the scale efficiency of the city by about } 0.358 \% \text {. In the } \\
\text { influence of control variables on SEC, the coefficient of TS is negative and significant. An } \\
\text { increase of } 1 \% \text { in the proportion of the secondary industry in GDP will lead to a decrease of } \\
\text { about } 0.319 \% \text { in the local city's scale efficiency, indicating that the rapid expansion of the } \\
\text { secondary industry is not conducive to the formation of scale effect. The coefficient of EDU } \\
\text { is positive and significant at the level of } 1 \% \text {. The increase of education expenditure by } 1 \% \\
\text { will increase the scale efficiency of the city by } 0.549 \% \text {. In the spatial lag coefficient of } \\
\text { variables, only the coefficient of INV is significant. If the investment of water supply and } \\
\text { drainage facilities in surrounding cities increases by } 1 \% \text {, the scale efficiency of the city will } \\
\text { be increased by about } 7.406 \% \text {. } \\
\text { Table } 7 \text {. Empirical results of spatial Durbin model (SEC) }\end{array}$}} \\
\hline & & & & & \\
\hline & & & & & \\
\hline & & & & & \\
\hline & & & & & \\
\hline & & & & & \\
\hline & & & & & \\
\hline & & & & & \\
\hline & & & & & \\
\hline & & & & & \\
\hline Variables & SLM(WX) & SEM(WX) & SDM(Wgeo) & SDM(Weco) & SDM(WX) \\
\hline \multirow[t]{2}{*}{$\mathrm{W} * \mathrm{SEC}$} & $0.374 * * *$ & $0.393 * * *$ & $0.414 * * *$ & $0.179 * * *$ & $0.358 * * *$ \\
\hline & $(0.057)$ & $(0.059)$ & $(0.075)$ & $(0.048)$ & $(0.058)$ \\
\hline \multirow[t]{2}{*}{ TS } & $-0.254 * * *$ & $-0.287 * * *$ & $-0.212 * *$ & $-0.313 * * *$ & $-0.319 * * *$ \\
\hline & $(0.071)$ & $(0.083)$ & $(0.097)$ & $(0.090)$ & $(0.094)$ \\
\hline TEC & 0.565 & 0.769 & 0.727 & 0.872 & 1.005 \\
\hline
\end{tabular}




\begin{tabular}{|c|c|c|c|c|c|}
\hline & $(0.669)$ & $(0.696)$ & $(0.693)$ & $(0.704)$ & $(0.698)$ \\
\hline \multirow[t]{2}{*}{ EDU } & $0.432 * * *$ & $0.514 * * *$ & $0.512 * *$ & $0.609 * * *$ & $0.549 * * *$ \\
\hline & $(0.172)$ & $(0.190)$ & $(0.208)$ & $(0.195)$ & $(0.197)$ \\
\hline \multirow[t]{2}{*}{ FDI } & 0.024 & 0.019 & 0.033 & 0.013 & -0.005 \\
\hline & $(0.046)$ & $(0.046)$ & $(0.045)$ & $(0.046)$ & $(0.045)$ \\
\hline \multirow[t]{2}{*}{ INV } & $0.566^{* *}$ & 0.322 & -0.279 & $-0.897 *$ & -0.385 \\
\hline & $(0.315)$ & $(0.428)$ & $(0.511)$ & $(0.510)$ & $(0.526)$ \\
\hline \multirow[t]{2}{*}{ PEO } & 0.349 & 0.432 & 0.156 & 0.454 & -0.056 \\
\hline & $(0.995)$ & (1.001) & $(0.970)$ & $(1.010)$ & $(0.983)$ \\
\hline \multirow[t]{2}{*}{$\mathrm{W}^{*} \mathrm{TS}$} & - & - & 0.275 & 0.111 & 0.354 \\
\hline & & & $(0.261)$ & $(0.139)$ & $(0.293)$ \\
\hline \multirow[t]{2}{*}{$\mathrm{W}^{*} \mathrm{TEC}$} & - & - & 2.984 & -1.709 & 0.927 \\
\hline & & & (3.817) & (1.587) & $(2.861)$ \\
\hline \multirow[t]{2}{*}{$\mathrm{W}^{*} \mathrm{EDU}$} & - & - & -0.458 & $-0.633^{*}$ & -0.150 \\
\hline & & & $(0.769)$ & $(0.355)$ & $(0.733)$ \\
\hline \multirow[t]{2}{*}{$\mathrm{W}^{*} \mathrm{FDI}$} & - & - & $-0.698 * * *$ & 0.095 & -0.314 \\
\hline & & & $(0.259)$ & $(0.139)$ & $(0.196)$ \\
\hline \multirow[t]{2}{*}{$\mathrm{W} * \mathrm{INV}$} & - & - & 1.997 & $2.518 * * *$ & $7.406 * * *$ \\
\hline & & & (2.658) & $(0.622)$ & $(1.961)$ \\
\hline \multirow[t]{2}{*}{$\mathrm{W}^{*} \mathrm{PEO}$} & - & - & 8.492 & -0.398 & -2.285 \\
\hline & & & $(6.603)$ & (2.979) & (4.124) \\
\hline $\mathrm{N}$ & 1274 & 1274 & 1274 & 1274 & 1274 \\
\hline $\mathrm{R}^{2}$ & 0.03 & 0.03 & 0.05 & 0.06 & 0.08 \\
\hline Two-way fixed & YES & YES & YES & YES & YES \\
\hline LR test for SAR & - & - & $12.70 * *$ & $21.78 * * *$ & $24.41 * * *$ \\
\hline LR test for SEM & - & - & $11.79^{*}$ & $22.22 * * *$ & $24.20 * * *$ \\
\hline
\end{tabular}

550 Table 8 reports the direct effect, spatial spillover effect (i.e. indirect effect) and total effect of 551 each variable. Direct effect refers to the influence of variables on the city, including both the direct 552 impact on the city and the spatial feedback effect. Spatial feedback effect refers to the effect of 553 spatial spillover effect of variables on surrounding cities, and the influence of surrounding cities 554 on the local city. Spatial spillover effect refers to the impact of variables on surrounding cities. 555 The total effect is the sum of direct effect and spatial spillover effect, which represents the impact 556 of variable change on all sample cities.

557 TS shows a significant negative total effect on GMLPI. An increase of $1 \%$ in the proportion 558 of the secondary industry in GDP will reduce the GWUE of YREB by about $0.714 \%$, which is 559 mainly due to the inhibition of technological progress. TEC and EDU promote the technical 560 progress of the city and surrounding cities at the same time. The increase of TEC and EDU by $1 \%$ 561 will increase the technical level of YREB by $5.241 \%$ and $1.719 \%$ respectively. The restraining 562 effect of FDI on GWUE is that it leads to the technology retrogression both the local city and the 563 surrounding cities. The increase of FDI by $1 \%$ will lead to the technology retrogression of YREB 564 about $0.417 \%$. INV can inhibit technological progress and improve scale efficiency. PEO has 565 significantly promoted the technical progress of YREB.

\begin{tabular}{llllll}
\hline Variable & effects & GMLPI & TC & PEC & SEC \\
\hline
\end{tabular}




\begin{tabular}{|c|c|c|c|c|c|}
\hline \multirow[t]{3}{*}{$\mathrm{TS}$} & Direct & $0.478 * * *$ & $-0.168^{*}$ & $0.864 * * *$ & $-0.316^{* * *}$ \\
\hline & Spillover & $-1.220 * * *$ & $-1.520 * * *$ & 0.547 & 0.353 \\
\hline & Total & $-0.741 * *$ & $-1.688 * * *$ & $1.412 * * *$ & 0.037 \\
\hline \multirow[t]{3}{*}{ TEC } & Direct & 0.219 & $2.184 * * *$ & $-2.923 * *$ & 0.976 \\
\hline & Spillover & 3.709 & $3.057^{*}$ & $12.330 * *$ & 0.866 \\
\hline & Total & 3.928 & $5.241 *$ & $9.407 *$ & 1.843 \\
\hline \multirow[t]{3}{*}{ EDU } & Direct & $0.263 * *$ & $0.791 * * *$ & $-0.755 * *$ & $0.569 * * *$ \\
\hline & Spillover & 1.216 & $0.928^{*}$ & -0.952 & -0.095 \\
\hline & Total & $1.479 * *$ & $1.719 * * *$ & -1.706 & 0.474 \\
\hline \multirow[t]{3}{*}{ FDI } & Direct & $-0.059^{*}$ & $-0.119 * *$ & 0.056 & -0.006 \\
\hline & Spillover & $-0.714 * * *$ & $-0.298^{*}$ & 0.003 & -0.313 \\
\hline & Total & $-0.773 * * *$ & $-0.417 * *$ & 0.058 & -0.318 \\
\hline \multirow[t]{3}{*}{ INV } & Direct & 0.065 & $-1.161 * *$ & $1.538^{*}$ & -0.369 \\
\hline & Spillover & 0.731 & $-4.186 * *$ & -5.283 & $7.518 * * *$ \\
\hline & Total & 0.796 & $-5.348 * * *$ & -3.745 & $7.149 * * *$ \\
\hline \multirow[t]{3}{*}{ PEO } & Direct & 0.495 & $3.268 * * *$ & -2.029 & -0.002 \\
\hline & Spillover & 7.692 & $21.031 * * *$ & $-17.100 * *$ & -1.944 \\
\hline & Total & 8.187 & $24.299 * * *$ & $-19.129 * *$ & -1.946 \\
\hline
\end{tabular}

\section{Discussion}

In the empirical analysis, we use the two-way fixed model and spatial Durbin model to investigate the spatial correlation and influencing factors of GWUE. This section will analyze the reasons for these results.

GMLPI, TC, PEC and SEC are all characterized by "high-high" or "low-low". The local city is affected by the technological changes of the surrounding cities in the same direction, which verifies the existence of "technology spillover effect", that is, the technological progress of the surrounding cities may contribute to the technological progress of the local city through enterprise exchange, labor flow, government cooperation and other channels (Aldieri et al, 2019; Aldieri et al, 2020). This reminds the government to strengthen synergy innovation. Promoting GWUE through technological progress requires the joint efforts of all cities. Higher PEC of the surrounding cities will also contribute to higher PEC of the local city. Pure technical efficiency, as an indicator of management level and technology utilization efficiency, is significantly affected by the flow of production factors and government environmental regulations. On the one hand, the convergence of production factors (such as capital and labor) in central city will weakens the sustainable development of water resources in surrounding cities, which is the "siphon effect" (Wang et al,2019; Feng et al,2019). TS, INV and PEO have a negative spatial imapct on PEC, which confirms the siphon effect. On the other hand, the government has the characteristics of "political competition" and "conpetition to the bottom" in sustainable development. The city will imitate other cities that have performed well in resources utilization efficiency, that is, the "imitation effect" (Yang et al, 2020). The imitation effect will make cities strengthen environmental regulations and force companies to improve their management capabilities and technology utilization. The reason that may lead to the "high-high" agglomeration characteristics of scale efficiency is that the progress of the local city's industrial chain and resource allocation will also lead to the 
optimization of scale economies in surrounding cities.

The influence of industrial structure on GWUE is manifested as a positive direct effect, a negative spatial spillover effect and total effect. Promoting the urban economy by industry is the development path of many cities in China. In order to attract industrial enterprises to set up factories in their cities, the government often resorts to land price concessions and tax reductions (Wang et al,2018). This helps companies reduce trade costs, improve management, and ultimately lead to an increase in pure technical efficiency. While, the rough expansion of the secondary industry may cause companies to deviate from the path of innovation-driven and specialized production, showing nagetive effects on TC and SEC. In addition, the spatial impact of industrial structure on GMLPI, TC and PEC is significantly negative, that is, the development of the secondary industry in the local city will inhibit the technological progress and pure technical efficiency of surrounding cities. The total effect of industrial structure is negative, that is, although the development of industial contribute to a higher GWUE in the local city, it is at the expense of the sustainable development of surrounding cities. Therefore, promoting the optimization of the indutrial structure and putting an end to the rough expansion of industries is the only way in the future.

TEC and EDU have significantly promoted technological peogress in both direct effects and spatial spillover effects. The proportion of sicence and technology expenditures in fiscal expenditures reflects the importance that cities place on cleaner peoduction technologies and sewage treatment technologies. High-intensity science and technology expenditures help companies improve the R\&D and utilization of high-tech (Miao et al,2017; Jin et al,2019), and ultimately lead to technological progress. Education expenditure has an important impact on improving the quality of the labor force and increasing the number of R\&D personnel ( $\mathrm{Li}$ et al,2019). The positive spatial spillover effects of TEC and EDU may be related to the high mobility of technology and labor. The clean production technology of the local city may flow to surrounding cities along with population migration and labor transfer, and bring advanced production technology to surrounding cities. For example, in recent years, China's cities have widely implemented the "talent introduction" program to encourage graduate and doctoral students to work in the city.

The impact of foreign direct investment on GWUE is that it leads to technological retrogression obviously. The impact of FDI on resource utilization efficiency is shown in two aspects: On the one hand, FDI could brings advanced cleaner production technology and improves the ability of urban innovation; On the other hand, in order to pursue lower pollution costs or cheap labor, foreign businessment may be more inclined to invest in the construction of factories that emit heavy pollution, that is, "pollution shelters", which will inhibit the utilization efficiency of green water resources (Liu et al, 2018; Cheng et al, 2020). The empirical results show that the negative impact of FDI is more significant. Similarly, the spatial impact of FDI on TC is also significantly negative, and eventually leads to a significant negative spatial impact of FDI on GWUE.

The investment in water supply and drainage facilities significantly improves the pure technical efficiency of the local city. Infrastructure has been widely proven to have a obvious positive impact on enterprise productivity. The investment in water supply and drainage facilities represents the level of infrastructure, which will improve the technical efficiency of enterprises by reducing the water cost of enterprises, and finally improve the urban GWUE. 


\section{Conclusions and policy recommendations}

In this paper, global Malmquist approach including unexpected output is used to calculate the Green Water-Use efficiency by using the panel data of 98 cities in the Yellow River Economic Belt from 2005 to 2018. The global Malmquist Luenberger productivity index is obtained and decomposed into technological change, pure technical efficiency change and scale efficiency change. Furthermore, SDM model is used to analyze the spatial spillover effect of GMLPI, TC, PEC, SEC and the influence of explanatory variables on the GWUE. The main results are as follows: (1) During the sample period, the global Malmquist Luenberger Productivity Index in the YREB showed a continuous upward trend, with an average annual growth rate of $7.86 \%$. The contribution of pure technical efficiency to GWUE was the largest (average annual growth rate was $3.84 \%$ ), the contribution of scale efficiency was the smallest (average annual growth rate was $1.87 \%$ ), and the average annual technical progress rate was $2.57 \%$. 2) GMLPI, TC, PEC and SEC are all characterized of "high-high" or "low-low" spatial agglomeration. Every 1\% rise in GMLPI, TC, PEC and SEC of surrounding cities will lead to the corresponding index growth of $0.321 \%$, $0.393 \%, 0.244 \%$ and $0.358 \%$ respectively. (3) The higher proportion of secondary industry in GDP will cause the progress of pure technical efficiency and inhibit technological innovation, and ultimately it will have a negative total effect on the GWUE of YREB. The increase of science and technology expenditure, education expenditure and population density will significantly promote the technological progress of the city and its surrounding cities. Foreign direct investment will lead to technology retrogression, and ultimately inhibit the growth of GWUE. Water supply and drainage infrastructure investment significantly improves the pure technical efficiency of the city, and has a positive spillover effect on the scale efficiency of surrounding cities.

According to conclusions, the government and enterprises can improve the green water-use efficiency through the following ways: (1) although the efficiency of GWUE shows a growth trend, it lacks stable growth motivity, inasmuch as TC, PEC and SEC fluctuate greatly. This requires the government and enterprises to continuously improve the management level, strengthen scientific and technological innovation, and provide stable and sustainable growth power for the efficiency of green water resources. (2) Strengthen cooperation and exchanges between cities. Sustainable development not only needs the efforts of a certain city, but also needs the cooperation and common development of all cities. Strengthening the exchange of culture, trade, science and technology among cities will help to break down regional barriers and promote the common development of cities. (3) Increasing investment in science and technology and education and improving the level of urban human capital is an important way to promote technological progress. Under the restriction of environmental regulation, scientific and technological innovation is the main driving force of high-quality economic development. Both government and enterprises should increase R\&D investment, strengthen technical exchange and promote technological progress. (4) We will increase the proportion of Green foreign direct investment. During the research period, foreign direct investment significantly inhibited the technological innovation of cities. The government should guide foreign investment to promote technological innovation and management efficiency of enterprises, instead of taking cities as "pollution shelters".

\section{Ackonwledgement}


We sincerely thank the following projects for their support on the study: "Young innovative talents" project of Harbin University of Commerce [2019CX16]; Graduate innovation project of Harbin University of Commerce [YJSCX2020-647HSD].

\section{Reference}

Aldieri, L., Carlucci, F., Vinci, C. P., Yigitcanlar, T., 2019. Environmental innovation, knowledge spillovers and policy implications: A systematic review of the economic effects literature. Journal of Cleaner Production. 239,118051.

Aldieri, L., Makkonen, T., Vinci, C. P., 2020. Environmental knowledge spillovers and productivity: A patent analysis for large international firms in the energy, water and land resources fields. Resources Policy. 69,101877.

An, Q. X., Wu, Q. F., Li, J. L., Xiong, B. B., Chen, X., H., 2019. Environmental efficiency evaluation for Xiangjiang River basin cities based on an improved SBM model and Global Malmquist index. Energy Economics. 81, 95-103.

Anselin, L., 2010. Thirty years of spatial econometrics. Pap. Reg. Sci. 89,3-25.

Bai, C. E., Ma, H., Pan, W. Q., 2012. Spatial spillover and regional economic growth in China. China Economic Review, 23, 982-990.

Casetti, E., 1986. The dual expansion method: An application for evalusting the effects of population growth on development. IEEE Transactions on Systems, Man and Cybernetics, 16(1), 29-39.

Chen, J., Wang, L. J., Li, Y. Y., 2020. Natural resources, urbanization and regional innovation capabilities. Resources Policy. 66,101643.

Cheng, Z. H., Li, L. S., Liu, J., 2020. The impact of foreign direct investment on urban PM2.5 polltion in China. Journal of Environmental Management. 265,110532.

Chikaraishi, M., Fujiawara, A., Kaneko, S., et al., 2015. The moderating effects of urbanization on carbon dioxide emissions: a latent class modeling approach. Technol Forecast Soc Change. 90,302-317.

Chung, Y. H., Fare, R., Grosskopf, S., 1997. Productivity and undesirable outputs: A directional distance function approach. Journal of Environmental Management. 51, 229-240.

Du, J., Chen, Y., Huang, Y., 2018. A Modified Malmquist-Luenberger Productivity Index: Assessing Environmental Productivity Performance in China. European Journal of Operational Research. 269(1), 171-187.

Elhorst, J. P., 2003. Specification and estimation of spatial panel data models. International Regional Science Review. 26, 244-268.

Elhorst, J. P., 2014. Matlab software for spatial panels. International Regional Science Review. 37(3), 1-17.

Emrouznejad, A., Yang, G. L., 2016. CO2 emissions reduction of Chinese light manufacturing industries: A novel RAM-based global Malmquist-Luenberger productivity index. Energy Policy. 96, 397-410.

Fare, R., Grosskopf, S., Lindgren, B., Roos, P., 1992. Productivity changes in Swedish pharamacies 1980-1989: A non-parametric Malmquist approach. Journal of Productivity Analysis. 3, 85-101.

Feng, Y. C., Wang, X. H., Du, W. C., Liu, J., Li, Y. X., 2019. Spatiotemporal characteristics 
and driving forces of urban sprawl in China during 2003-2017. Journal of Cleaner Production. 241,118061.

Geng, Q. L., Ren, Q. F., Nolan, R. H., Wu, P., Yu, Q., 2019. Assessing China's agricultural water use efficiency in a green-blue water perspective: A study based on data envelopment analysis. Ecological Indicators. 96(1),329-335.

Getis, A., 2007. Reflections on spatial autocorrelation. Regional Science \& Urban Economics. 37,491-496.

Guan, R. D., Tian, L. X., Li, W. C., 2019. Analysis of Influencing Factors on Energy Efficiency of Yangtze River Delta Urban Agglomeration Based on Spatial Heterogeneity. Energy Procedia. 158,3234-3239.

Haining, R., 1978. The moving average model for spatial interation. Transactions of the Institute of British Geographers, 3(2), 202-225.

Hao, Y., Deng, Y. X., Lu, Z. N., Chen, H., 2018. Is environmental regulation effective in China? Evidence from city-level panel data. Journal of Cleaner Production. 188, 966-976.

Hong, J. K., Zhong, X. Y., Guo, S., Liu, G. W., Shen, Q. P., Yu, T., 2019. Water-energy nexus and its efficiency in China's construction industry: Evidence from province-level data. Sustainable Cities and Society. 48,101557.

Hong, Y., Lyu, X., Chen, Y., Li, W., 2020. Industrial agglomeration externalities, local governments' competition and environmental pollution: Evidence from Chinese prefecture-level cities. Journal of Cleaner Production. 277,123455.

Hu, J. L., Wang, S. C., Yeh, F. Y., 2006. Total-factor water efficiency of regions in China. Resources Policy. 31(4), 217-230.

Huang, G. B., Zhang, J., Yu, J., Shi, X. P., 2020. Impact of transportation infrastructure on industrial pollution in Chinese cities: A spatial econometric analysis. Energy Economics. 92,104973.

Huang, R., Chen, G. W., Lv, G. N., Malik, A., Shi, X. P., Xie, X. T., 2020. The effect of technology spillover on $\mathrm{CO} 2$ emissions embodied in China-Australia trade. Energy Policy, $144,111544$.

Jin, W., Zhang, H. Q., Liu, S. S., Zhang, H. B., 2019. Technological innovation, environmental regulation, and green total factor efficiency of industrial water resources. Journal of Cleaner Production. 211, 61-69.

Kumar, S., 2006. Environmentally sensitive productivity growth: A global analysis using Malmquist-Luenberger index. Ecological Economics. 56(2), 280-293.

Kumar, S., Managi, S., 2010. Environment and productivities in developed and developing countries: The case of carbon dioxide and sulfur dioxide. Journal of Environmental Management. 91(7), 1580-1592.

Li, J., See, K. F., Chi, J., 2019. Water resources and water pollution emissions in China's industrial sector: A green-biased technological progress analysis. Journal of Cleaner Production. 229, 1412-1426.

Liu, H. B., Liu, Y. F., Wang, H. N., Yang, J. Y., Zhou, X., 2014. Research on the coordinated development of greenization and urbanization based on system dynamics and data envelopment analysis_ A case study of Tianjin. Journal of Cleaner Production. 214, 195-208.

Liu, Q. Q., Wang, S. J., Zhang, W. H., Zhang, D. S., Li, J. M., 2018. Does foreign direct 
investment affect environmental pollution in China's cities? A spatial econometric perspective. Science of The Total Environment. 613-614,521-529.

Liu, K., Lin, B., 2019. Research on influencing factors of environmental pollution in China: a spatial economietric analysis. Journal of Cleaner Production. 206,356-364.

Long, K. S., Pijanowski, B. C., 2017. Is there a relationship between water scarcity and water use efficiency in China? A national decadal assessment across spatial scales. Land Use Policy. 69,502-511.

Long, R. Y., Ouyang, H. Z., Guo, H. Y., 2020. Super-slack-based measuring data envelopment analysis on the spatial-temporal patterns of logistics ecological efficiency using global Malmquist Index model. Environmental Technology \& Innovation. 18, 100770.

Lv, Y. L., Chen, W., Cheng, J. Q., 2019. Modelling dynamic impacts of urbanization on disaggregated energy consumption in China: A spatial Durbin modelling and decomposition approach. Energy Policy, 133, 110841.

Lv, Z. K., Li, S. S., 2021. How financial development affects CO2 emissions: A spatial econometric analysis. Journal of Environmental Management. 227, 111397.

Ma, Y. R., Ji, Q., Fan, Y., 2016. Spatial linkage analysis of the impact of regional economic activities on PM2.5 pollution in China. Journal of Cleaner Production. 139, 1157-1167.

Mavi, N. K., Mavi, R. K., 2019. Energy and environmental efficiency of OECD countries in the context of the circular economy: Common weight analysis for malmquist productivity index. Journal of Environmental Management. 247,651-661.

Miao, C. L., Fang, D. B., Sun, L. Y., Luo, Q. L., 2017. Natural resources utilization efficiency under the influence of green technological innovation. Resources, Conservation and Recycling. 126, 153-161.

Moran, P., 1950. Notes on continuous stochastic phenomena. Biometrika, 37, 17-33.

Ouedraogo, A., 2016. Local economic impact of boom and bust in mineral resource extraction in the United States: A spatial econometrics analysis. Resources Policy. 50,292-305.

Pastor, J. T., Lovell, C. A. K., 2005. A golbal Malmquist productivity index. Economics Letters. 88, 266-271.

Piao, S. R., Li, J., Ting, C. J., 2019. Assessing regional environmental efficiency in China with distinguishing weak and strong disposability of undesirable outputs. Journal of Cleaner production. 227,748-759.

Shao, S., Li, X., Cao, J. H., 2019. Urbanization promotion and haze pollution governance in China. Economic Research Journal, 54(02), 148-165. (In Chinese)

Song, Y., Yeung, G., Zhu, D. L., Zhang, L. X., Xu, Y., Zhang, L. Y., 2020. Efficiency of logistics land use: The case of Yangtze River Economic Belt in China, 2000-2017. Journal of Transport Geography. 88,102851.

Tobler, W. R., 1970. A computer movie simulation urban growth in the Detroit region. Econ. Geogr. 46,234-240.

Wang, W. J., Ren, L. J., Guo, Q. W., Chen, T., 2012. Predicating energy demand and carbon emissions of the Yellow River delta high-efficiency eco-economic zone. Energy Procedia. $14,229-234$.

Wang, C., Engels, A., Wang, Z. H., 2018. Overview of research on China's transition to low-carbon development: The role of cities, technologies, industries and the energy system. Renewable and Sustainable Energy Reviews. 81(1), 1350-1364 
Wang, Y. X., Wang, Y., Su, X. L., Qi, L., Liu, M., 2019. Evaluation of the comprehensive carrying capacity of interprovincial water resources in China and the spatial effect. Journal of Hydrology, 575, 794-809.

Wang, S. J., Wang, J. Y., Fang, C. L., Li, S. J., 2019. Estimating the impacts of urban form on CO2 emission efficiency in the Pearl River Delta, China. Cities. 85,117-129.

Wang, K. L., Pang, S. Q., Ding, L. L., Miao, Z., 2020. Combining the biennial MalmquistLuenberger index and panel quantile regression to analyze the green total factor productivity of the industrial sector in China. Science of The Total Environment. 739,140280 .

Wang, S. B., Zhao, C., Liu, H. B., Tian, X. L., 2020b. Exploring the spatial spillover effects of low-grade coal consumption and influencing factors in China. Resources Policy. 101906.

Wu, L. P., Chen, Y., Mohammad, R. F., Liu, W. J., 2018. Estimation of China's macro-carbon rebound effect: Method of integrating Data Envelopment Analysis production model and sequential Malmquist-Luenberger index. Journal of Cleaner Production. 198,1431-1442.

Xu, L., Tan, J. L., 2020. Financial development, industrial structure and natural resource utilization efficiency in China. Resources Policy. 66,101642.

Yan, J. N., 2019. Spatiotemporal analysis for investment efficiency of China's rural water conservancy based on DEA model and Malmquist productivity index model. Sustainable Computing: Informatics and Systems. 21,56-71.

Yang, M., Yan, X. H., Li, Q. Y., 2020. Study on the impact of environmental regulation on the efficiency of industrial pollution control in China. China population, resources and environment. 30(9), 54-61. (In Chinese)

Yao, X. 1., F, W., Zhang, X. L., Wang, W. X., Zhang, C. T., You, S. Q., 2018. Measurement and decomposition of industrial green total factor water efficiency in China. Journal of Cleaner Production. 198,1144-1156.

Zhu, X. H., Li, Y., Zhang, P. F., Wei, Y. G., Zheng, X. Y., Xie, L. L., 2019. Temporal-spatial characteristics of urban land use efficiency of China's 35mega cities based on DEA: Decomposing technology and scale efficiency. Land Use Policy. 88,104083. 
Figures

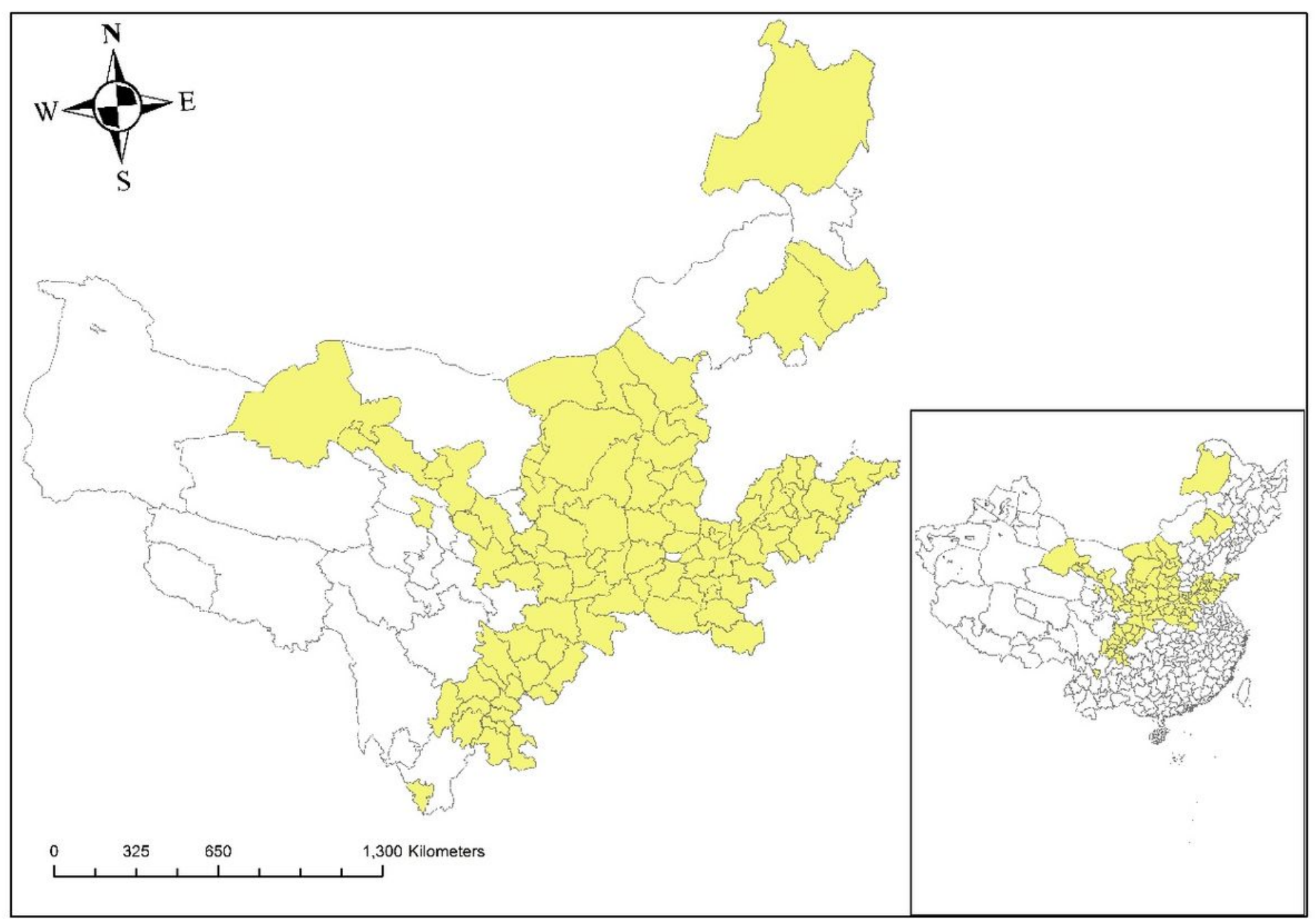

\section{Figure 1}

Yellow River Economic Belt Note: The designations employed and the presentation of the material on this map do not imply the expression of any opinion whatsoever on the part of Research Square concerning the legal status of any country, territory, city or area or of its authorities, or concerning the delimitation of its frontiers or boundaries. This map has been provided by the authors. 


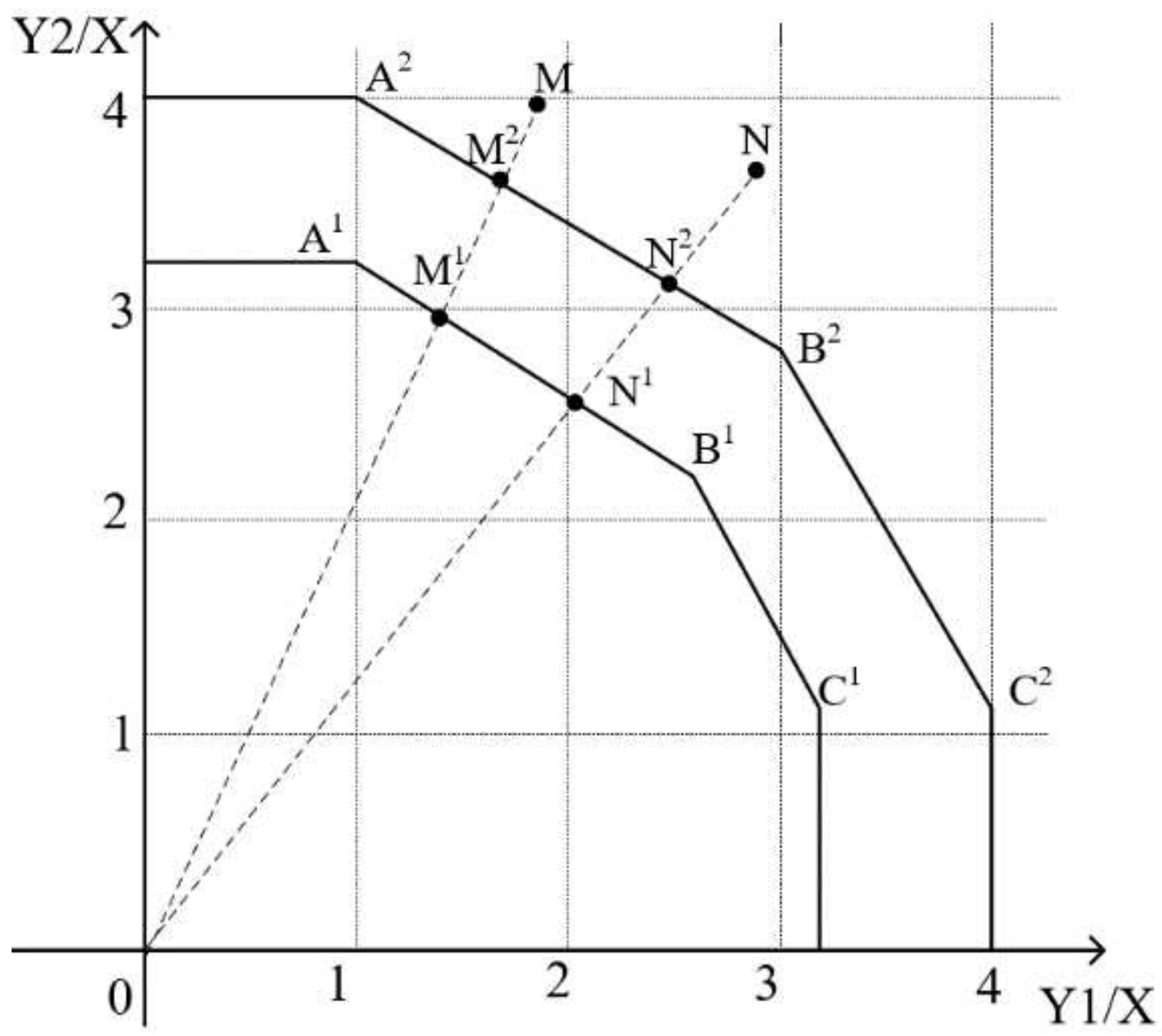

Figure 2

Output-oriented Malmquist productivity index

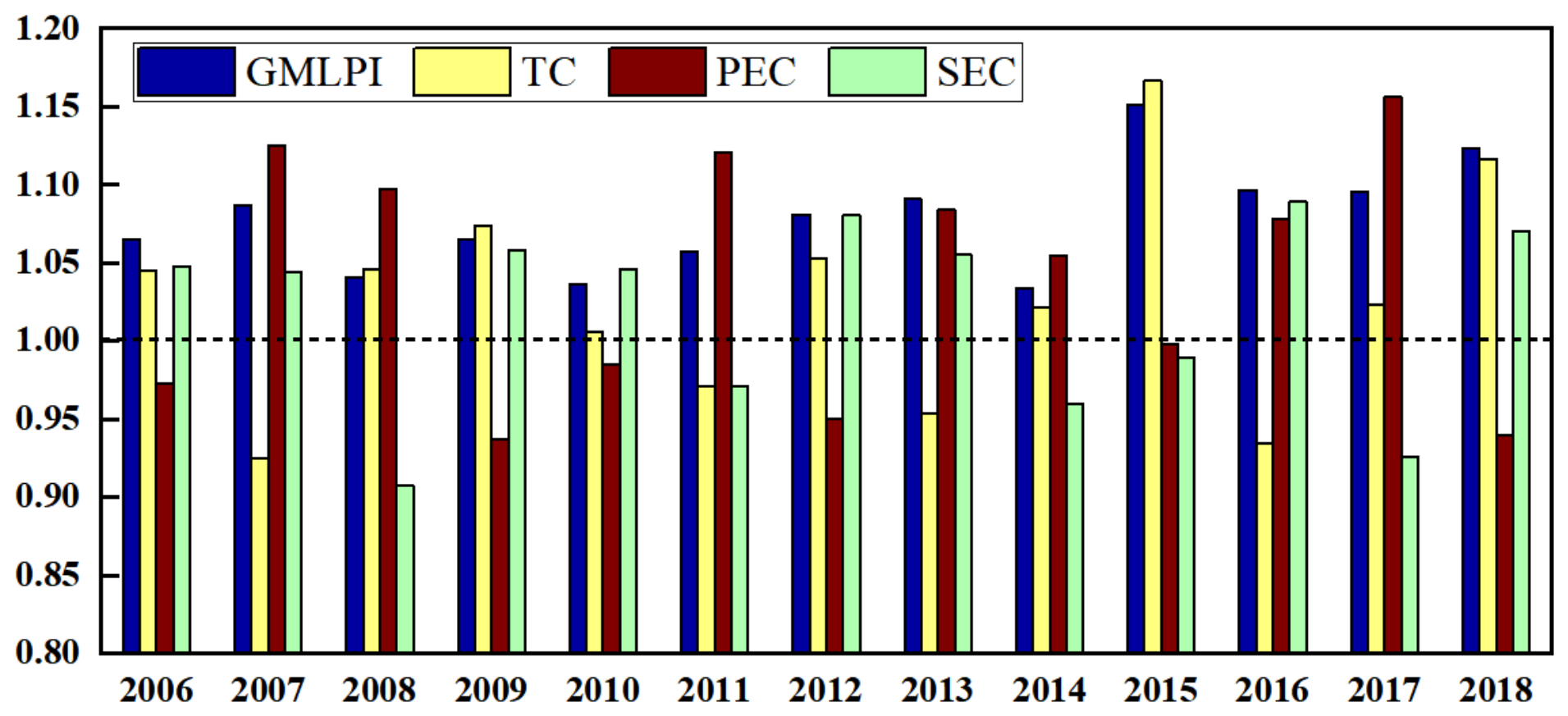


Figure 3

Trend of GMLPI and its decomposition index of YREB between 2006-2018
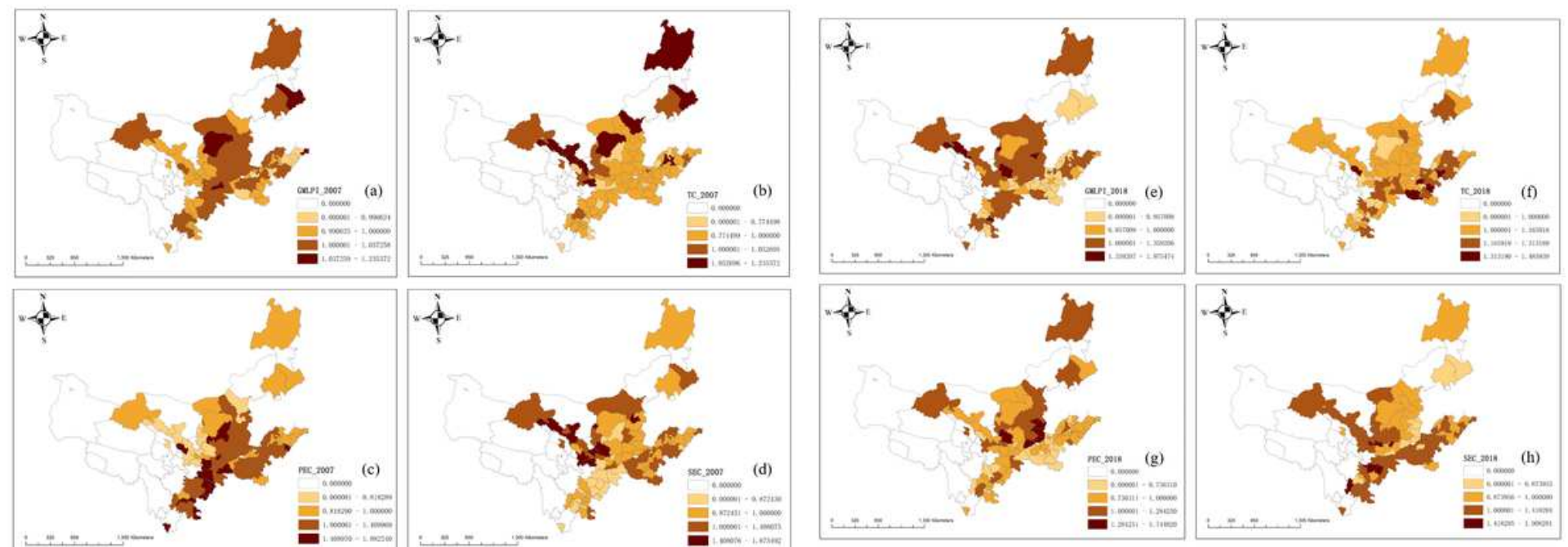

Figure 4

Result of econometric models Note: The designations employed and the presentation of the material on this map do not imply the expression of any opinion whatsoever on the part of Research Square concerning the legal status of any country, territory, city or area or of its authorities, or concerning the delimitation of its frontiers or boundaries. This map has been provided by the authors. 

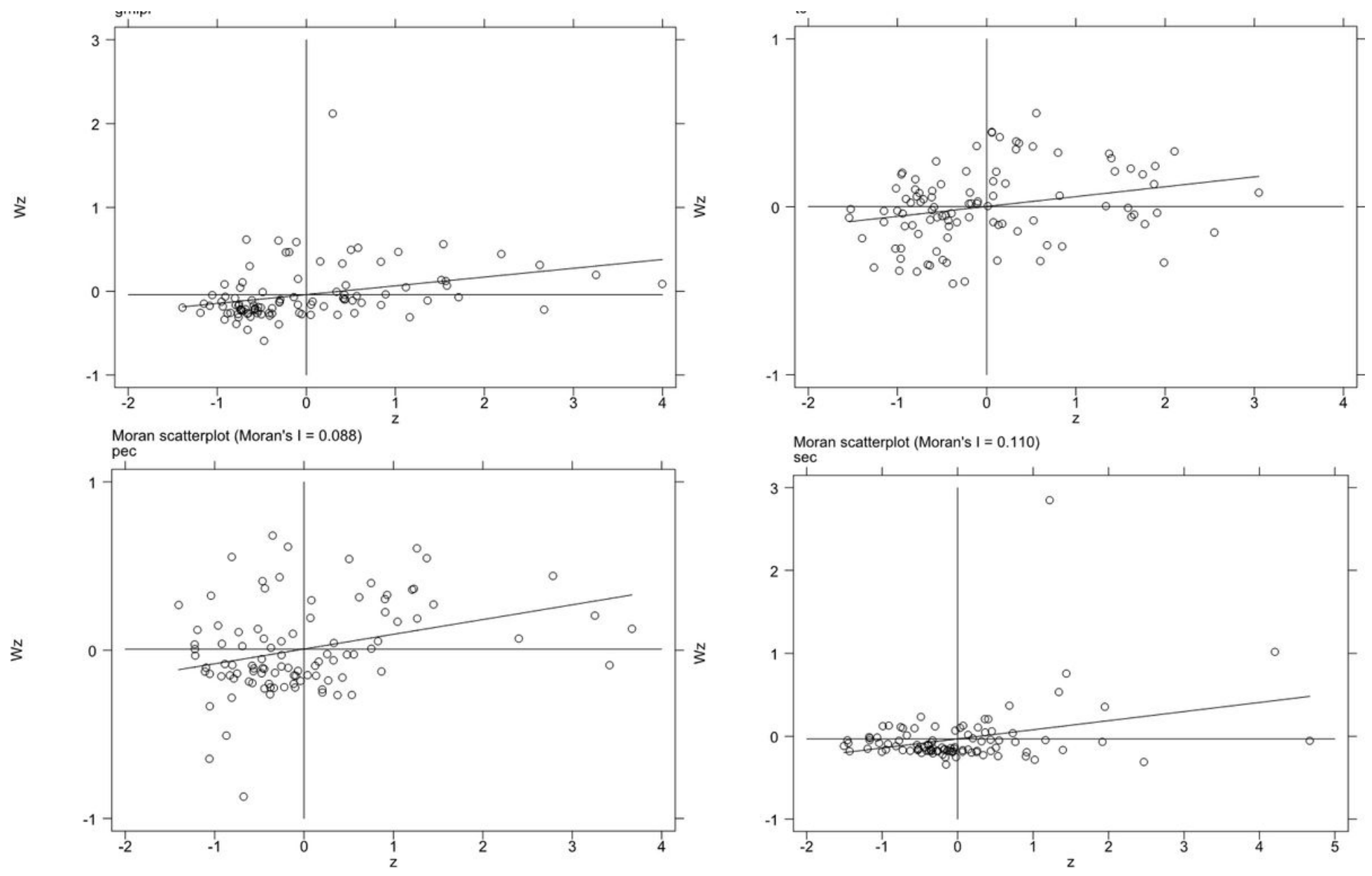

Figure 5

Moran's I scatter map of GMLPI 